\title{
Diapycnal oxygen supply to the tropical North Atlantic oxygen minimum zone
}

\author{
T. Fischer, D. Banyte, P. Brandt, M. Dengler, G. Krahmann, T. Tanhua, and M. Visbeck \\ GEOMAR Helmholtz Centre for Ocean Research, Kiel, Germany
}

Correspondence to: T. Fischer (tfischer@geomar.de)

Received: 1 October 2012 - Published in Biogeosciences Discuss.: 17 October 2012

Revised: 21 May 2013 - Accepted: 3 June 2013 - Published: 26 July 2013

\begin{abstract}
The replenishment of consumed oxygen in the open ocean oxygen minimum zone (OMZ) off northwest Africa is accomplished by oxygen transport across and along density surfaces, i.e. diapycnal and isopycnal oxygen supply. Here the diapycnal oxygen supply is investigated using a large observational set of oxygen profiles and diapycnal mixing data from years 2008 to 2010 . Diapycnal mixing is inferred from different sources: (i) a large-scale tracer release experiment, (ii) microstructure profiles, and (iii) shipboard acoustic current measurements plus density profiles. From these measurements, the average diapycnal diffusivity in the studied depth interval from 150 to $500 \mathrm{~m}$ is estimated to be $1 \times 10^{-5} \mathrm{~m}^{2} \mathrm{~s}^{-1}$, with lower and upper $95 \%$ confidence limits of $0.8 \times 10^{-5} \mathrm{~m}^{2} \mathrm{~s}^{-1}$ and $1.4 \times 10^{-5} \mathrm{~m}^{2} \mathrm{~s}^{-1}$. Diapycnal diffusivity in this depth range is predominantly caused by turbulence, and shows no significant vertical gradient. Diapycnal mixing is found to contribute substantially to the oxygen supply of the OMZ. Within the OMZ core,

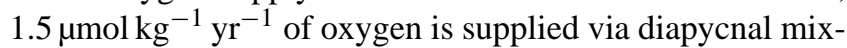
ing, contributing about one-third of the total demand. This oxygen which is supplied via diapycnal mixing originates from oxygen that has been laterally supplied within the upper Central Water layer above the OMZ, and within the Antarctic Intermediate Water layer below the OMZ. Due to the existence of a separate shallow oxygen minimum at about $100 \mathrm{~m}$ depth throughout most of the study area, there is no net vertical oxygen flux from the surface layer into the Central Water layer. Thus all oxygen supply of the OMZ is associated with remote pathways.
\end{abstract}

\section{Introduction}

The open oceans host distinct permanent regions of low oxygen concentration (oxygen minimum zones, OMZs), many of them situated near the eastern boundaries of the tropical oceans outside the equatorial belt. Tropical OMZs have some common features. They coincide with weak mean circulation, and their core is found between 200 and $700 \mathrm{~m}$ depth. However, their spatial extent and oxygen levels are diverse. While moderate oxygen levels are encountered in the Atlantic OMZs, very low to vanishing oxygen levels are found in the Indian and Pacific OMZs (Karstensen et al., 2008; Paulmier and Ruiz-Pino, 2009). OMZs are regions of diverse microbial and biochemical activity (Lam and Kuypers, 2011; Wright et al., 2012), but pose a challenge or even lethal threat to certain marine animal species, with increasing numbers of threatened species the lower the oxygen level (Vaquer-Sunyer and Duarte, 2008; Ekau et al., 2010; Prince et al., 2010). With anthropogenic climate change projections of a warming ocean and increased stratification, a net decline of the global ocean oxygen content is expected, and also an expansion and intensification of OMZs is anticipated (Keeling et al., 2010). These expectations are in line with observations over the past decades, which indicate a recent decline in global subsurface ocean oxygen content (Stramma et al., 2010; Helm et al., 2011), and also indicate a recent expansion of individual OMZs (Whitney et al., 2007; Bograd et al., 2008; Stramma et al., 2008b). Particularly the tropical North Atlantic OMZ off northwest Africa has shown a significant oxygen decline and expansion over the past 50 years (Stramma et al., 2008b, 2009). Consequences of oxygen decline for biogeochemical cycles, marine organisms and ecosystems are expected to be profound, particularly in 
regions that are already low in oxygen (Ekau et al., 2010; Gruber, 2011; Wright et al., 2012).

The existence and position of oxygen minimum layers can basically be explained by a balance between oxygen loss due to respiration of organic matter (i.e. oxygen consumption rate), and oxygen supply via ocean circulation (i.e. ventilation) (Wyrtki, 1962). Ventilation can be achieved by advective and diffusive supply. Here, supply is defined as excess of oxygen flux into a fixed volume over oxygen flux out of the volume. A suitable coordinate system to describe ocean circulation is density coordinates, which divide ventilation into processes that act along surfaces of constant density (isopycnal) and across surfaces of constant density (diapycnal). This splits ventilation processes into four contributing terms: diapycnal diffusion (molecular, turbulent eddy, and double diffusive), diapycnal advection, isopycnal diffusion (mainly eddy), and isopycnal advection. Interpreting the oxygen balance, the consumption rate may be seen as an external forcing exerted by sinking organic matter that originates in the surface layer, while parameters of ocean circulation such as mean flow and eddy diffusivities set the system's reaction to the forcing. This reaction is then manifested in the resulting shape of the oxygen concentration field, and in the magnitude of associated diapycnal and isopycnal oxygen fluxes which replenish the oxygen consumed. In this view, feedbacks on organic matter supply caused by long-term changes of the circulation, or the effect of very low oxygen levels close to zero on consumption, are ignored.

However, quantitative knowledge about processes controlling OMZs is limited. Neither oxygen consumption rates nor the oxygen supply by the different ventilation processes mentioned above are well constrained by observations (Keeling et al., 2010). Furthermore, numerical model simulations do not well reproduce the observed global oxygen distribution (Duteil and Oschlies, 2011; Najjar et al., 2007; Meissner et al., 2005). Despite this weakness, simulations under future climate scenarios consistently predict a global oxygen loss of the ocean (Keeling et al., 2010). But how the extent and intensity of individual tropical OMZs will change in the future, is not clear: oxygen solubility, stratification, circulation, and organic export production are all affected by climate change (Bopp et al., 2001, 2002), and each of them, by their effect on ventilation and consumption, sensitively influences the extent and intensity of OMZs (Gruber, 2011). Simulation efforts have resulted in diverse projections of the future volume of OMZs, reaching from expansion (Matear and Hirst, 2003; Oschlies et al., 2008) to neutral (Gruber, 2011) to contraction (Duteil and Oschlies, 2011). The latter study found even the sign of the predicted trend being sensitive to the amount of background diapycnal mixing, and thus indicates that quantifying diapycnal processes may be important for the understanding of OMZs.

Recent observational progress concerning ventilation of OMZs has been achieved in the tropical North Atlantic OMZ using two different approaches. In an idealized frame- work of an advection-diffusion model fit to observations, Brandt et al. (2010) quantified the contributions of physical processes replenishing oxygen at a given isopycnal surface within the OMZ. The diapycnal oxygen supply was estimated by assuming a diapycnal diffusivity and calculating a diapycnal oxygen curvature from the observed oxygen distribution and the simulated oxygen concentration at that isopycnal surface. In another approach, Banyte et al. (2012) determined the diapycnal diffusivity by a large-scale tracer release experiment in the oxycline above the core of the tropical North Atlantic OMZ to be $(1.19 \pm 0.18) \times 10^{-5} \mathrm{~m}^{2} \mathrm{~s}^{-1}$. This value is of the same order as determined in previous studies in the thermocline of the open ocean, and much lower than in boundary regimes and other hotspots of diapycnal mixing. Nevertheless, we will show below that diapycnal mixing seems to be an important process for the ventilation of this open ocean OMZ, and one of the major controls on concentration level and shape of the oxygen field. This is in line with the model-based finding of diapycnal diffusivity controlling the future evolution of OMZs (Duteil and Oschlies, 2011).

The main objective of the present study is to quantify diapycnal oxygen supply and its vertical structure in the tropical North Atlantic OMZ. Diapycnal supply is the sum of supplies by diapycnal diffusion and by diapycnal advection, but oxygen supply by diapycnal advection is assumed negligible in the depth range associated with the OMZ (cf. Sect. 4.5). Therefore in the following, we focus on estimating the diapycnal supply by diapycnal diffusion. In order to quantify the diapycnal diffusive supply within the OMZ, we use an extensive ship-based observational dataset of simultaneous oxygen and mixing measurements. To date, diapycnal oxygen supply in the open ocean has not been determined from appropriate measurements elsewhere. Nevertheless, the basic method to evaluate Fick's first law of diffusion, using simultaneous profiles of diffusivities and concentrations, has been used in other contexts to estimate fluxes of solutes and is well established. Turbulence profiles and nutrient profiles have been used in various shelf regions to estimate nutrient supply to surface waters (Sharples et al., 2001, 2007; Rippeth et al., 2009; Hales et al., 2005, 2009; Schafstall et al., 2010). Similarly, Kock et al. (2012) used microstructure turbulence and nitrous oxide gradients on the shelf and in the open ocean of the tropical Atlantic to estimate gas flux to surface waters.

The dataset was compiled from several cruises to the OMZ since 2008, when observation activities in the tropical North Atlantic intensified in the framework of the German research programmes SFB754, SOPRAN, and NORTH ATLANTIC, and the EU project EUROSITES. Diapycnal diffusivity was obtained by microstructure profiling and shipboard acoustic current profiling. The mentioned tracer release experiment - GUTRE (Guinea Upwelling Tracer Release Experiment, Banyte et al., 2012) - happened simultaneously and provides an independent integrative estimate of diapycnal diffusivity for the depth range which the tracer patch occupied. The available diffusivity data overlap in the depth range 150 


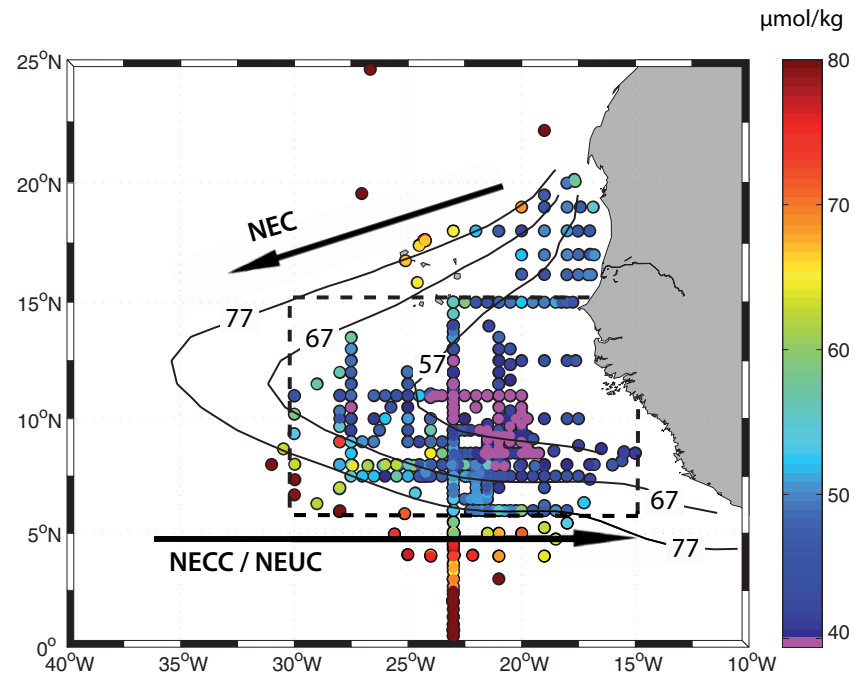

Fig. 1. Oxygen concentrations (coloured dots) in the core of the deep oxygen minimum, which is situated at depths between 350 and $500 \mathrm{~m}$. Oxygen data were collected during the time period of 2008 through 2010 of the simultaneous tracer release experiment GUTRE, and stem from seven ship cruises in total. Black labelled lines are oxygen core concentration isolines, the minimum concentrations derived from World Ocean Atlas WOA09 (Garcia et al., 2010) by vertical spline interpolation. The WOA $77 \mu \mathrm{mol} \mathrm{kg}^{-1}$ and $67 \mu \mathrm{mol} \mathrm{kg}{ }^{-1}$ isolines roughly enclose the observed $60 \mu \mathrm{mol} \mathrm{kg}-1$ and $50 \mu \mathrm{mol} \mathrm{kg}^{-1}$ core concentrations in the period 2008 to 2010 , while the WOA $57 \mu \mathrm{mol} \mathrm{kg}^{-1}$ isoline does not well describe the $40 \mu \mathrm{mol} \mathrm{kg}^{-1}$ observations. The WOA 77 line is used here to define the extent of the OMZ. The dashed black line defines the analysis box (in depth interval 150 to $500 \mathrm{~m}$ ) that comprises most of the available mixing data. NEC: North Equatorial Current, NECC: North Equatorial Countercurrent, NEUC: North Equatorial Undercurrent.

to $500 \mathrm{~m}$, which comprises the OMZ core and the oxycline above. Based on the microstructure, and acoustic and tracer data, we provide an estimate of the average diapycnal diffusivity for the tropical North Atlantic OMZ at 150 to $500 \mathrm{~m}$ depth (Sect. 4.1), which may also serve for future model studies. We further estimate the average diapycnal oxygen supply profile (Sect. 4.2 to 4.5 ), which makes it possible to draw some conclusions on this OMZ's supply pathways and their importance. The extensive database further allows the deduction of some statistical information, which may become useful for similar future observational studies, e.g. the observed horizontal independence of vertical oxygen gradients and according diapycnal mixing (Sect. 3.7), or the estimated size of confidence limits for the average diapycnal diffusivity if using smaller datasets (Sect. 4.1).

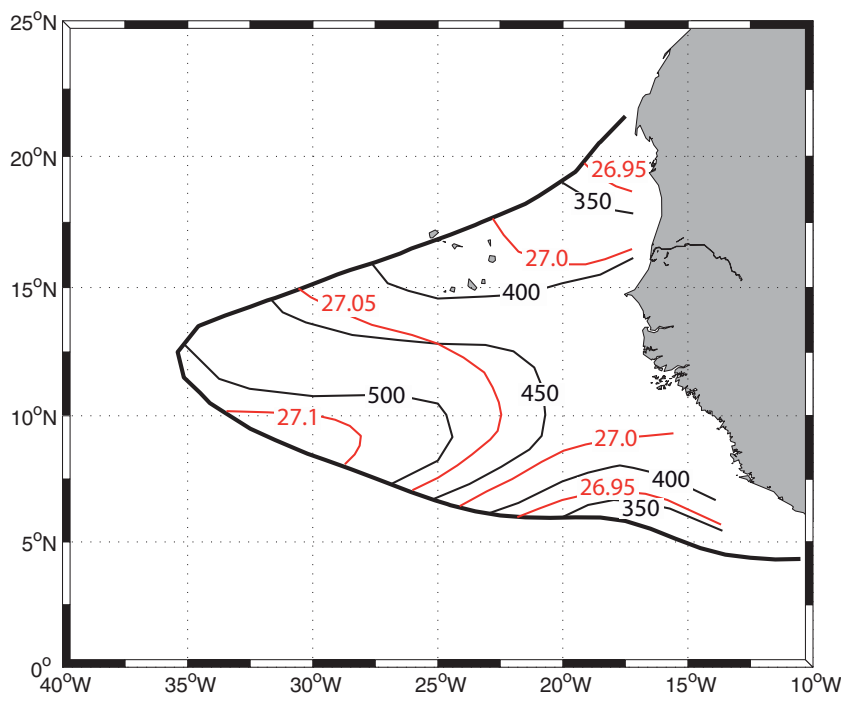

Fig. 2. Vertical position of the deep oxygen minimum core in depth coordinates (black isolines, metres) and in potential density coordinates (red isolines, $\mathrm{kg} \mathrm{m}^{-3}$ ). Isoline shapes are mostly derived from observations in the period 2008 to 2010 . Where observational gaps were too large, isolines were completed by following the shapes of isolines based on World Ocean Atlas WOA09 (Garcia et al., 2010).

\section{Study site}

\subsection{Tropical North Atlantic oxygen minimum zone}

The OMZ in the tropical North Atlantic Ocean (Fig. 1) approximately matches the Guinea Dome region (Siedler et al., 1992). This coincidence is most likely caused by both, OMZ and Guinea Dome, being linked to the zone of weak circulation between North Equatorial Current (NEC at $20^{\circ} \mathrm{N}$ to $15^{\circ} \mathrm{N}$ ) and North Equatorial Countercurrent/Undercurrent $\left(\mathrm{NECC} / \mathrm{NEUC}\right.$ at $5^{\circ} \mathrm{N}$ ) (Karstensen et al., 2008). Vertical oxygen profiles in this region typically exhibit two oxygen minimum layers at core depths of about $100 \mathrm{~m}$ and $450 \mathrm{~m}$ (Fig. 4). The shallow minimum with a thickness of about $50 \mathrm{~m}$ is pronounced in 80 to $90 \%$ of the oxygen profiles. Profiles lacking a shallow oxygen minimum were found to be scattered throughout the study area, with a tendency to become more frequent towards the southern part of the OMZ. The deep oxygen minimum at a depth range of about $300 \mathrm{~m}$ to $700 \mathrm{~m}$ exists in all profiles in the region, and shows core concentrations of typically 40 to $60 \mu \mathrm{mol} \mathrm{kg}^{-1}$. These minimum concentrations are on average $40 \mu \mathrm{mol} \mathrm{kg}^{-1}$ lower than the core concentrations of the shallow minimum. In the following we will only study the deeper, more voluminous and more intense oxygen minimum. Its core is at the interface between Antarctic Intermediate Water (AAIW) and the overlying Central Water (Stramma et al., 2008a) and has shown a noticeable oxygen decline during the last five decades (Stramma et al., 2008b, 2009). The vertical position of the core in the $\mathrm{OMZ}$ region neither perfectly follows isobaths 


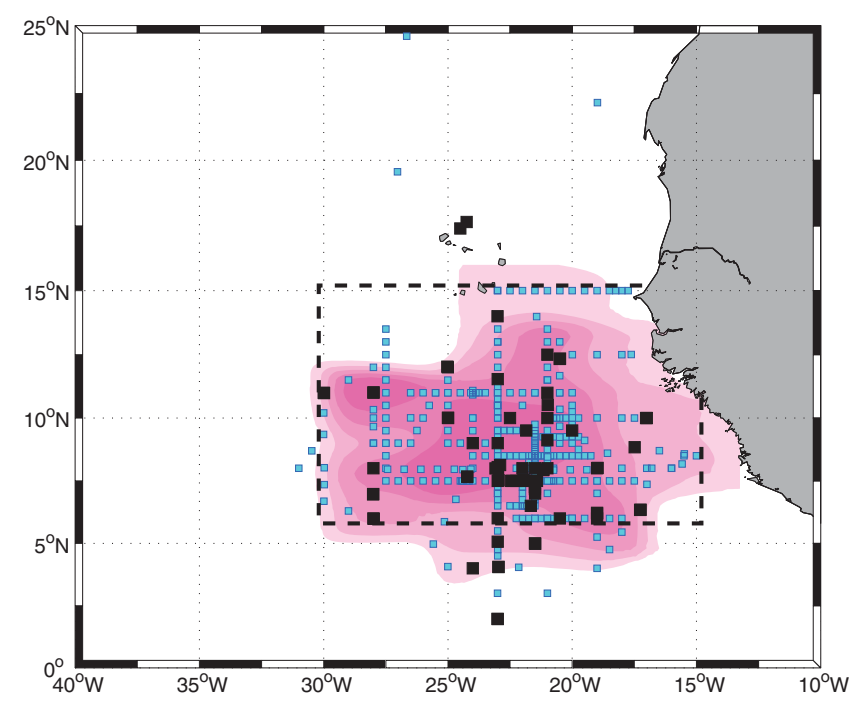

Fig. 3. Minimum covered area of tracer patch after 30 months (magenta filled contour) as well as locations of microstructure measurements (black squares) and stations with shear data from $75 \mathrm{kHz}$ vessel-mounted ADCP (blue squares) during cruises in the period 2008 to 2010 . The chosen analysis box is marked with a dashed black line.

nor isopycnals (Fig. 2). However it is better aligned to isopycnals: the standard deviation of the core vertical position in the OMZ is $60 \mathrm{~m}$ with respect to the mean core depth of $425 \mathrm{~m}$, and $40 \mathrm{~m}$ with respect to the mean core isopycnal $27.03 \mathrm{~kg} \mathrm{~m}^{-3}$. The position of the maximum oxygen gradient above the OMZ core (at about $300 \mathrm{~m}$ depth and the isopycnal $26.85 \mathrm{~kg} \mathrm{~m}^{-3}$ ) will be called deep oxycline throughout this study in order to distinguish it from the oxycline just below the mixed layer (Fig. 4). Approximately, the deep oxycline divides the Central Water into upper and lower Central Water, in accordance with the definition used by Kirchner et al. (2009). We define horizontal OMZ extent by the $60 \mu \mathrm{mol} \mathrm{kg}^{-1}$ isoline of oxygen core concentration as observed between 2008 and 2010 (Fig. 1). The reason for this choice is that the region encompassed by the $60 \mu \mathrm{mol} \mathrm{kg}-1$ isoline includes as much as possible of the low oxygen region of the tropical Northeast Atlantic, while it excludes adjacent regimes which are better ventilated, particularly those associated with the eastward flow of the NECC/NEUC in the south and with the subtropical gyre at Cape Verde front in the north. Furthermore $60 \mu \mathrm{mol} \mathrm{kg}{ }^{-1}$ can be considered as a limit to hypoxia for marine animals (Diaz, 2001; VaquerSunyer and Duarte, 2008; Ekau et al., 2010; Keeling et al., 2010). Meridional oxygen variations in the OMZ are found to be associated with a system of alternating zonal current bands, in which eastward/westward currents coincide with higher/lower oxygen concentration (Stramma et al., 2008a; Brandt et al., 2010).

\subsection{Analysis box}

For the analysis of diapycnal oxygen flux, a box is chosen from 6 to $15^{\circ} \mathrm{N}$ latitude, 30 to $15^{\circ} \mathrm{W}$ longitude, and 150 to $500 \mathrm{~m}$ depth. This box covers large parts of the OMZ at its $60 \mu \mathrm{mol} \mathrm{kg}{ }^{-1}$ isoline of core concentration, and it is centred at the location of the lowest observed core concentrations just below $40 \mu \mathrm{mol} \mathrm{kg}{ }^{-1}$ (Fig. 1). Nevertheless it omits some parts of the OMZ: to the northeast a region associated with upwelling, to the west a part where we expect core concentrations between 50 and $60 \mu \mathrm{mol} \mathrm{kg}-1$, and to the southeast a part inside the shelf region and exclusive economic zones of some west African states. The chosen analysis box is the place where diapycnal mixing can be constrained best because it was horizontally and vertically filled with tracer in the later phase of tracer release experiment GUTRE (after 20 and 30 months), and because most supplemental diapycnal mixing measurements that are suitable for our analysis were conducted during GUTRE surveys inside the analysis box (Fig. 3). The depth interval of interest extends from below the shallow oxygen minimum across the deep oxycline down to the core of the deep oxygen minimum (Fig. 4). It is thus confined to the upper part of the deep oxygen minimum layer, and diapycnal oxygen flux to the OMZ from the welloxygenated waters below the OMZ core cannot be quantified in this study. Stratification $\left(N^{2}\right)$ is near-constant through the chosen depth interval for individual profiles, but varies from $1 \times 10^{-5}$ to $2 \times 10^{-5} \mathrm{~s}^{-2}$ in the region. The higher $N^{2}$ values are found towards the southeast. For a detailed description of the $N^{2}$ distribution, refer to Banyte et al. (2012).

\section{Data and methods}

\subsection{Diapycnal diffusivity, diapycnal flux, diapycnal flux divergence and averaging}

In the open ocean, diapycnal mixing that is sustained by molecular diffusion is often enhanced by turbulence from breaking internal waves (e.g. Staquet and Sommeria, 2002), and can additionally be enhanced by double diffusive processes (e.g. St. Laurent and Schmitt, 1999). In this study, diapycnal diffusivity $K$ will be used to describe diapycnal mixing and to estimate the diapycnal flux of water mass properties. Due to the presence of turbulence in the ocean, diapycnal property fluxes are greatly enhanced compared to property fluxes in a non-turbulent fluid. Diapycnal diffusivities are thus strongly governed by the turbulent flow characteristics of the oceanic region, albeit in principle, $K$ must be differentiated with respect to the water mass property in focus. As in our case the appropriate $K_{\text {oxygen }}$ is inaccessible, other more accessible $K$ values were used as approximate estimates. If not stated otherwise, $K$ throughout the paper stands for $K_{\text {oxygen }}$, the one this study aims at. Other meanings of $K$ will be indicated by indices, which may specify the technique 


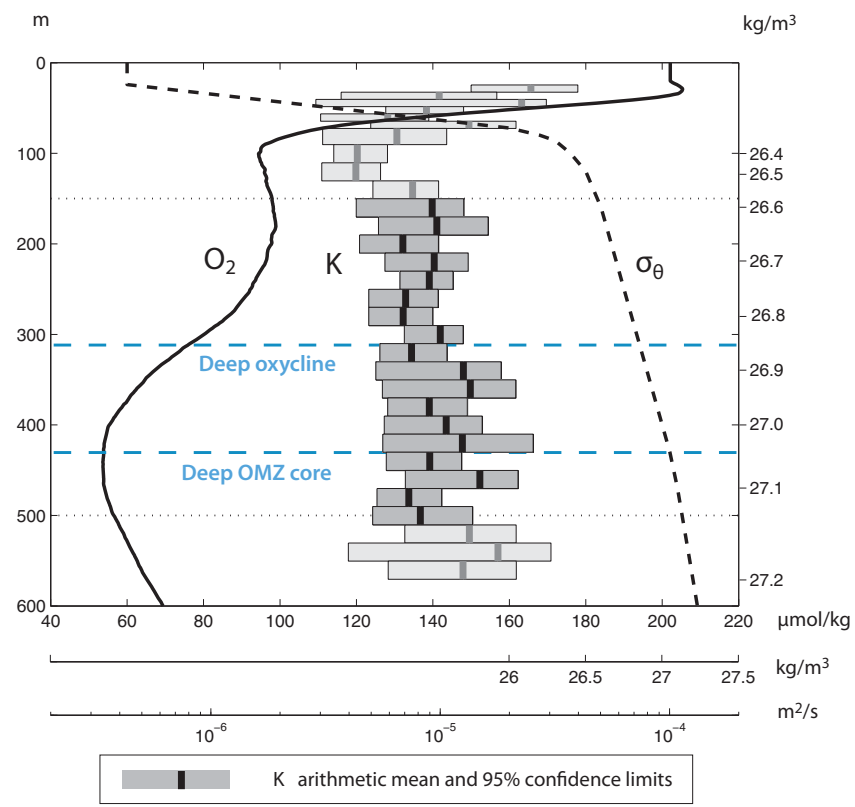

Fig. 4. Profiles of oxygen concentration, diapycnal diffusivity $K$ from microstructure measurements, and potential density, averaged across the entire chosen analysis region of the OMZ. $K$ values are arithmetic averages for $20 \mathrm{~m}$ bins within their $95 \%$ confidence intervals. Dotted lines mark the depth interval where diapycnal oxygen flux is evaluated. This is the depth interval where depth intervals for $K$ estimates from the different methods overlap.

to obtain $K$ ( $\left.K_{\mathrm{TRE}}, K_{\mathrm{MSS} / \mathrm{ADCP}}\right)$ or the property the specific $K$ is valid for (e.g. $K_{\text {tracer }}, K_{\rho}$ ) or the mechanism that caused $K$ ( $K_{\text {turb }}$ from mechanical turbulence, $K_{\mathrm{DD}}$ from double diffusive enhancement). We use three different measurement strategies to obtain estimates of $K_{\text {oxygen }}$. (1) The diapycnal spreading of a tracer during GUTRE (Sect. 3.4) yielded $K_{\mathrm{TRE}}$, which is an estimate for both $K_{\text {tracer }}$ and $K_{\text {oxygen }}$, assuming that dissolved oxygen behaves similar to the tracer. (2) Measurements of the strength of mechanical turbulence by using a microstructure profiler (Sect. 3.5) delivered an estimate of the diapycnal diffusivity of mass $K_{\rho} . K_{\rho}$ can serve as an estimate for $K_{\text {oxygen }}$ if (a) turbulent diffusivity is much greater than molecular diffusivities and (b) double diffusion is negligible (St. Laurent and Schmitt, 1999; Ferrari and Polzin, 2005). (3) Velocity profiles from vessel-mounted acoustic Doppler current profilers (vmADCP) yielded estimates of vertical shear spectra (Sect. 3.6) which served to parameterize $K_{\rho}$. As this parameterization (Appendix A) is based on the measured microstructure profiles, the use of vmADCP measurements is not an independent method, but it helps in substantially enhancing the database.

The diapycnal oxygen flux $\Phi$ can be estimated using Fick's first law of diffusion if simultaneous profiles of oxygen concentration (Sect. 3.3) and diapycnal diffusivity are available. The diapycnal flux is a down-gradient flux perpendicular to density surfaces driven by diapycnal diffusivity.
The necessary diapycnal gradient of oxygen concentration to calculate $\Phi$ can be approximated by the vertical gradient of oxygen concentration so that

$\Phi=-\rho K_{\text {oxygen }} \frac{\partial}{\partial z} c$,

with $\rho$ water density in $\mathrm{kg} \mathrm{m}^{-3}, K_{\text {oxygen }}$ diapycnal diffusivity of oxygen in $\mathrm{m}^{2} \mathrm{~s}^{-1}, c$ oxygen concentration in $\mu \mathrm{mol} \mathrm{kg} \mathrm{kg}^{-1}$ and $\Phi$ resulting diapycnal flux in $\mu \mathrm{mol} \mathrm{m} \mathrm{m}^{-2} \mathrm{~s}^{-1}$.

When regarding the oxygen budget in a volume enclosed by two isopycnal surfaces, the diapycnal influx across the first isopycnal surface does not need to be of the same magnitude as the diapycnal outflux across the second isopycnal surface. The difference of the two diapycnal fluxes is described by the diapycnal flux divergence $\nabla \Phi$, which can be approximated by the vertical derivative of $\Phi, \partial \Phi / \partial z . \nabla \Phi$ is

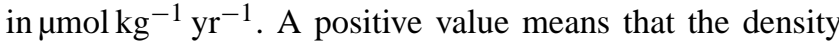
layer loses oxygen via a diapycnal flux imbalance. In order to quantify the net oxygen supply of the density layer caused by diapycnal processes, it is necessary to observe $-\nabla \Phi$.

Ultimately, the goal is to determine averaged profiles of diapycnal diffusivities, fluxes, and flux divergences for the entire OMZ. Thus averaging along isopycnal surfaces is a necessary processing step which will be denoted by brackets, as for example in $\langle K\rangle$. Unless otherwise specified, the brackets refer to arithmetic averaging after objective mapping on isopycnal surfaces. For the objective mapping of $K$, the decorrelation scale was determined by a semivariogram to be $0.5^{\circ}$. Confidence limits for isopycnal averages are determined from the combined individual error distributions, taking into account the reduced degrees of freedom caused by the spatial correlation. Another kind of averaging that will be used in this study is averaging in diapycnal direction, and will be denoted by an overbar, as for example in $\bar{K}$, so that a total average for the entire analysis box in this example would be $\langle\bar{K}\rangle$.

\subsection{Data overview}

The data were collected during four cruises in November 2008 (RV Merian MSM10/1), November and December 2009 (RV Meteor M80/1 and M80/2), and October 2010 (RV Meteor M83/1) during the tracer surveys for GUTRE. Oxygen was measured using a conductivity-temperature-depth profiler (CTD) with added Clark-type oxygen sensors (CTD$\mathrm{O}_{2}$ ). For most of the oxygen profiles, simultaneous estimates of diapycnal diffusivity $K_{\rho}$ from microstructure profiles or vmADCP were available. In total, 400 complete profiles consisting of CTD- $\mathrm{O}_{2}$ and diapycnal diffusivity were collected in the analysis box (Fig. 3). The tracer surveys delivered one additional independent space-time-averaged estimate of diapycnal diffusivity for the entire region for the period of 2008 through 2010. Another three cruises in February, March, and April 2008 (RV L'Atalante GEOMAR/3 and GEOMAR/4, and RV Merian MSM08/1) delivered 110 additional oxygen 
profiles, but without simultaneous $K$ estimates. That is why these oxygen measurements only helped in outlining the OMZ (Fig. 1), but did not enter the oxygen flux calculation.

\subsection{Oxygen and CTD data calibration}

Each ship station that is considered here comprises a CTD$\mathrm{O}_{2}$ profile down to at least the deep oxygen minimum core at about 400 to $500 \mathrm{~m}$. On the four cruises evaluated here (MSM10/1, M80/1, M80/2, and M83/1) similar CTD/rosette systems were used, consisting of a Sea-Bird 911plus CTD equipped with dual Sea-Bird temperature, conductivity, and oxygen sensors. During each of the cruises, several hundred water samples were collected to calibrate the conductivity and oxygen sensors using a Guildline Autosal 8400B salinometer and a Winkler titration stand. The deviations between the in situ conductivity measured by the Sea-Bird CTD and the high-accuracy on-board water sample measurements using salinometers were used to derive a correction to the CTD's conductivity linear in pressure, temperature, and CTD conductivity itself. After applying the corrections, the resulting absolute accuracy of the CTD salinity values was estimated to $0.005,0.002,0.002$, and 0.003 for the cruises MSM10/1, M80/1, M80/2, and M83/1, respectively. Laboratory calibration suggests the accuracy of the temperature and pressure measurements to be better than $0.002 \mathrm{~K}$ and $1.5 \mathrm{dbar}$, respectively. Similar to conductivity, the deviations between the CTD and the on-board Winkler titrations were used to derive a correction to the CTD's oxygen measurements. The chosen correction was linear in pressure, temperature, and oxygen, and we estimate the absolute accuracy of the CTD's oxygen measurements to be better than $3,1,1$, and $1 \mu \mathrm{mol} \mathrm{kg}{ }^{-1}$ for the respective four cruises.

While these estimates of the CTD data's absolute uncertainty and their only slowly varying corrections are useful for comparisons with other observations, for our analysis of vertical oxygen gradients, an estimate of the oxygen sensor noise and precision is more relevant. We found that the oxygen sensors had a typical instrument noise of less than $0.2 \mu \mathrm{mol} \mathrm{kg}^{-1}$ (95th percentile of the signal residuals, after removing the slowly varying signal). The estimates of vertical oxygen gradients used here are based on 1 dbar averages of the CTD oxygen measurements, which were originally recorded at $24 \mathrm{~Hz}$. This results in a noiseinduced uncertainty of the vertical oxygen gradient of less than $0.03 \mu \mathrm{mol} \mathrm{kg}^{-1} \mathrm{~m}^{-1}$ when evaluated at 2 dbar intervals.

\subsection{K estimated from GUTRE}

The deliberate Guinea Upwelling Tracer Release Experiment (GUTRE) was performed in the deep oxycline in the tropical North Atlantic OMZ in order to obtain a time- and spaceintegrated estimate of diapycnal diffusivity at the OMZ's upper limit. Ninety-two kilograms of the halocarbonic compound $\mathrm{SF}_{5} \mathrm{CF}_{3}$ (Ho et al., 2008) were released in April 2008 at $8^{\circ} \mathrm{N} 23^{\circ} \mathrm{W}$ at the isopycnal surface $\sigma_{\theta}=26.88 \mathrm{~kg} \mathrm{~m}^{-3}$. The expanding tracer patch was sampled during three survey campaigns (MSM10/1, M80 and M83/1) 7, 20, and 30 months after injection. After 20 and 30 months, the tracer essentially covered the analysis box horizontally and vertically. From the increase of the vertical extent of the isopycnally integrated tracer distribution, the time-space-averaged diapycnal diffusivity was estimated to be $\langle\bar{K}\rangle_{\mathrm{TRE}}=(1.19 \pm 0.18) \times$ $10^{-5} \mathrm{~m}^{2} \mathrm{~s}^{-1}$ (Banyte et al., 2012). The uncertainty at $95 \%$ confidence level is based on bootstrapping and measurement errors. During all three surveys the mean tracer concentration profile showed no significant skew.

\section{5 $K$ estimated from microstructure data}

As an independent method from GUTRE, diapycnal diffusivities were also estimated using microscale shear recordings from a loosely tethered microstructure profiler. During the tracer survey cruises, the microstructure profiler MSS90D (termed MSS in the following) of Sea and Sun Technology, Trappenkamp, Germany, was used immediately after certain CTD casts. Usually three profiles in a series down to $500 \mathrm{~m}$ at about $0.5 \mathrm{~m} \mathrm{~s}^{-1}$ sink velocity were collected at these ship stations. In total, MSS data could be obtained on 45 ship stations in the analysis box. On the way to estimate diapycnal diffusivities from MSS, the signal from two to four airfoil shear sensors at the profiler head was converted to profiles of microscale vertical shear. Then the dissipation rate $\epsilon$ of turbulent kinetic energy could be estimated from the power spectrum of microscale vertical shear by using a vertical wavenumber range free of instrument vibrational noise and by assuming local isotropy (Oakey, 1982; Stips and Prandke, 2000). The diapycnal diffusivity of mass, $K_{\rho}$, was inferred from the Osborn parameterization $K_{\rho}=\Gamma \epsilon N^{-2}$ (Osborn, 1980 ), with $\Gamma$ the dimensionless dissipation ratio that is related to mixing efficiency. $\Gamma$ was set at 0.2 because simulation data by Shih et al. (2005) suggest this value to be appropriate for weak to moderate turbulence, which is essentially what was found in the analysis box: the average value of the turbulence activity parameter $\epsilon v^{-1} N^{-2}$ calculated from all data available for this study amounts to 41 , and less than $8 \%$ of the $\epsilon v^{-1} N^{-2}$ values exceed 100 . When taking into account the eddy diffusivity parameterization suggested by Shih et al. (2005) for situations of $\epsilon v^{-1} N^{-2}>100$, the average $K_{\rho}$ reduces by only $2.5 \%$. The value 0.2 is further supported by findings of St. Laurent and Schmitt (1999), who report $\Gamma$ between 0.15 and 0.25 in turbulence-dominated regimes with weak mean shear - conditions that were also met in the analysis box. For the analyses of this study, vertical averages of $\epsilon$ and $N^{2}$ for the depth interval $150 \mathrm{~m}$ through $500 \mathrm{~m}$ were used to infer a single average $K_{\rho \text {,MSS }}$ per ship station via the Osborn parameterization. Using narrower depth bins to calculate $K_{\rho \text {,MSS }}$ would only marginally change the results. At the same time, growing measurement errors in $N^{2}$, which go hand in hand with narrower depth bins 
chosen, would introduce a bias to the $K_{\rho}$ estimated from the Osborn parameterization. The uncertainty of $K_{\rho \text {,MSS }}$ was estimated from quantifiable errors to be $60 \%$ on a $95 \%$ confidence level. This uncertainty estimate is based on the following reasoning: the microstructure probe delivers one estimate of $\epsilon$ per metre depth, which leaves us with roughly $1000 \epsilon$ values in the $150 \mathrm{~m}$ to $500 \mathrm{~m}$ depth range per station of three profiles. These $\epsilon$ values are arithmetically averaged following Davis (1996). To estimate the uncertainty of the $\epsilon$ average, we follow an approach used by Ferrari and Polzin (2005) in a similar situation where they calculated vertically averaged $K_{\rho}$ values from microstructure measurements in the eastern North Atlantic. We find a vertical decorrelation scale in our $\epsilon$ profiles of $5 \mathrm{~m}$ (comparable to the findings of Ferrari and Polzin (2005) in water depths $<800 \mathrm{~m}$ ), which leaves us with roughly 200 degrees of freedom to reduce the spread of the $\epsilon$ distribution. Nonetheless, the $\epsilon$ uncertainty remains the main contributor to the total uncertainty of the $K_{\rho}$ estimate, together with sensor uncertainties that have to be accounted for as systematic errors for the duration of an MSS station. There is also a minor contribution from uncertainty in $N^{2}$, and there certainly is some contribution from the choice of $\Gamma$, but of unknown amount.

\section{6 $K$ estimated from vmADCP}

The possibility to obtain additional estimates of $K_{\rho}$ from current velocity profiles via vmADCP substantially enhanced the number of "complete" station data comprising CTD plus oxygen plus $K_{\rho}$, which could be used to infer diapycnal oxygen flux; the number rising from 45 to 400 inside the analysis box (Fig. 3). The method is based on the observation that finescale vertical shear with vertical wavelengths of the order of ten to some hundreds of metres and dissipation rate $\epsilon$ of turbulent kinetic energy can be related (Gargett, 1976; Gregg, 1989). It had been used before with lowered ADCP data (Polzin et al., 2002; Kunze et al., 2006). The main processing strategy for the application to vmADCP data during ship stations was as follows: (1) generate velocity profiles with noise low enough so that vertical shear signals which are of the order of the open ocean background level can still be detected; (2) obtain spectra of vertical shear of horizontal velocity in the finescale vertical wavenumber range; (3) obtain dissipation rate $\epsilon$ from shear power spectral level $\Phi_{\mathrm{S}}$ by a parameterization (see Appendix) which uses MSS measurements for calibration; (4) obtain $K_{\rho}$ from $\epsilon$ and CTD-derived stratification by the Osborn parameterization as in Sect. 3.5.

Minutiae of processing were the following: during three survey cruises MSM10/1, M80/2 and M83/1, an RDI Ocean Surveyor $75 \mathrm{kHz}$ vmADCP continuously recorded currents down to $600 \mathrm{~m}$ depth at $8 \mathrm{~m}$ vertical bin size. The broadband mode that we used, a high ping frequency $\left(36 \mathrm{~min}^{-1}\right)$, usually calm sea conditions, and a final two-dimensional filtering step of velocity fields in depth-time-space, resulted in $1 \mathrm{~min}$-average velocity data of $0.01 \mathrm{~m} \mathrm{~s}^{-1}$ precision at
$95 \%$ level (for technical details refer to Fischer, 2011). From the $1 \mathrm{~min}$-averaged and filtered velocity profiles, spectra of vertical shear were calculated for 150 to $533 \mathrm{~m}$ depth and corrected following Polzin et al. (2002) for variance losses caused by ADCP binning, tilting, and ping averaging. The resulting $1 \mathrm{~min}$ shear power spectra were usable in the wavenumber band from $1 / 128 \mathrm{cpm}$ to $1 / 38.4 \mathrm{cpm}$. Power spectra were averaged over the duration of a ship station, and served to estimate a single value of shear power spectral level $\Phi_{\mathrm{S}}$ for that ship station and the entire depth interval 150 to $500 \mathrm{~m}$. $\Phi_{\mathrm{S}}$ led to $\bar{\epsilon}_{\mathrm{ADCP}}$ after using the parameterization Eq. (A5), and to $\bar{K}_{\rho, \mathrm{ADCP}}$ after using the Osborn parameterization. The uncertainty of $\bar{K}_{\rho, \mathrm{ADCP}}$ was estimated to be a factor of 2.7 at $95 \%$ confidence level, resulting from measurement noise, discrete spectrum estimation, and error progression through, as well as unexplained variance of, the parameterization Eq. (A5).

\subsection{Implications of $\boldsymbol{K}$ derived from different sources}

Apart from physical differences of the derived diapycnal diffusivities, the three applied methods delivered $K$ estimates which also differ in the grade to which they represent spatially and temporally averaged quantities. The immediate result of the MSS measurements were vertical profiles of $K_{\rho, \text { MSS }}$ for each ship station at about $0.5 \mathrm{~m}$ depth resolution, the result of the vmADCP processing was a single vertical average $\bar{K}_{\rho \text {,ADCP }}$ for each ship station, and the TRE delivered essentially one time-space-average $\langle\bar{K}\rangle_{\mathrm{TRE}}$ for the entire analysis box during the period 2008 to 2010 . For the further processing of $K-$ i.e. to deliver estimates of $\langle\bar{K}\rangle_{\text {oxygen }}$, a profile of diapycnal oxygen flux, $\langle\Phi\rangle$, and a profile of diapycnal flux divergence - we assume that $K$ can be treated as vertically homogeneous through the used depth interval 150 to $500 \mathrm{~m}$ for timescales larger than several days. This assumption is supported by the MSS-derived average profile $\langle K\rangle_{\rho, \mathrm{MSS}}$, which shows no significant gradient at 150 to $500 \mathrm{~m}$ (Fig. 4), as well as by GUTRE tracer profiles, which showed no significant deviation from a Gaussian (Banyte et al., 2012). Vertical homogeneity at 150 to $500 \mathrm{~m}$ is also suggested by the majority of individual density profiles in the analysis box, which show a near constant stratification. The assumption of vertically homogeneous $K$ implies that (1) vertical averaging of $K_{\rho, \text { MSS }}$ for MSS data is equivalent to averaging of longer time series, which we lack, and (2) $\bar{K}$ defines the level of the assumed constant $K$ profile at each ship station; in that sense $\bar{K}$ and $K$ are equivalent for the process of isopycnal averaging (e.g. to estimate $\langle\Phi\rangle$ ). Another property of our dataset is the statistical independence of the oxygen gradient and $\bar{K}_{\rho}$ from MSS/ADCP, as shown in Fig. 5 for all depths between 150 and $500 \mathrm{~m}$. The independence is expressed in the equivalence of $\left\langle K_{\rho} \times \nabla c\right\rangle$ and $\left\langle K_{\rho}\right\rangle \times\langle\nabla c\rangle$. This also means that $\langle\Phi\rangle$ may be calculated as $\langle\langle K\rangle \times \nabla c\rangle$, i.e. $K$ may also be treated as if it were laterally homogeneous (but this time on the long timescale of the TRE 


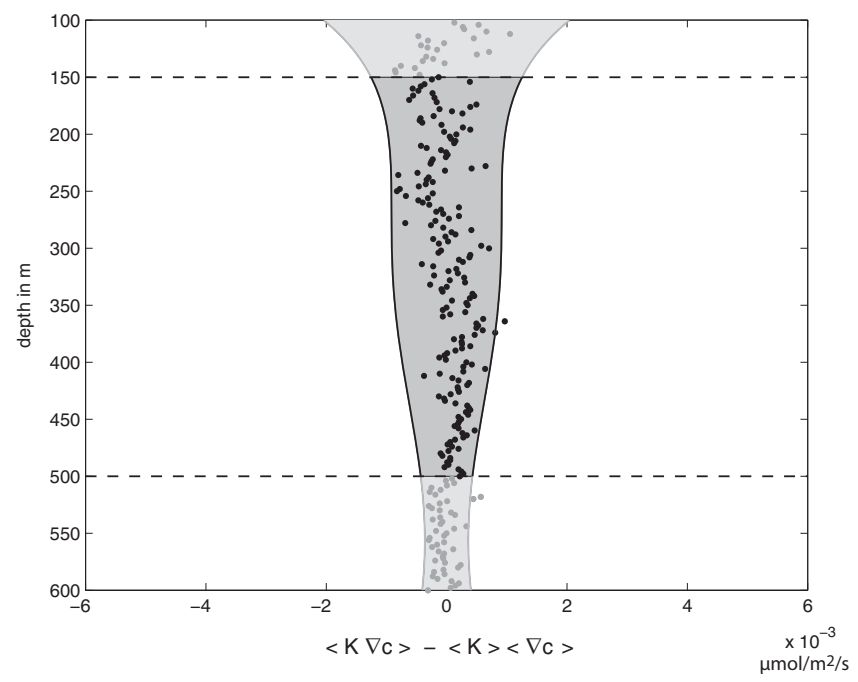

Fig. 5. Difference between the lateral average of local diapycnal fluxes and the product of laterally averaged diapycnal diffusivity and laterally averaged oxygen gradient as a function of depth. The difference is found to be smaller than the $95 \%$ confidence interval of $\langle K \cdot \nabla c\rangle$ (grey shading) for most depth layers. Dashed lines mark the analysis depth interval where $K$ observations exist.

duration). The estimates of this effective long-term largescale $K$ will be denoted $\langle\bar{K}\rangle_{\text {TRE }}$ and $\langle\bar{K}\rangle_{\text {MSS /ADCP (MSS and }}$ ADCP combined because the ADCP method was calibrated with MSS measurements).

\section{Results and discussion}

\subsection{Diapycnal diffusivities}

Estimates of diapycnal diffusivity were derived from the deliberate tracer release experiment GUTRE as one integrative value $\langle\bar{K}\rangle_{\mathrm{TRE}}$, and from MSS/ADCP methods as $\bar{K}_{\mathrm{MSS} / \mathrm{ADCP}}$ for individual locations in the analysis box. The values are to be compared and evaluated to what degree they can serve as estimates for $\langle\bar{K}\rangle_{\text {oxygen }}$.

The $\bar{K}_{\text {MSS/ADCP }}$ were arithmetically averaged after objective mapping on isopycnal surfaces (Section 3.1) to allow comparison to $\langle\bar{K}\rangle_{\mathrm{TRE}}$. The resulting $\langle\bar{K}\rangle_{\mathrm{MSS} / \mathrm{ADCP}}$ as an estimate for $\langle\bar{K}\rangle_{\rho}$ was $(0.95 \pm 0.15) \times 10^{-5} \mathrm{~m}^{2} \mathrm{~s}^{-1}$. $\langle\bar{K}\rangle_{\text {TRE }}$ from GUTRE as an estimate for $\langle\bar{K}\rangle_{\text {tracer }}$ was $(1.2 \pm 0.2) \times 10^{-5} \mathrm{~m}^{2} \mathrm{~s}^{-1}$. Both uncertainty estimates only represent the quantifiable errors, i.e. a lower limit to the true uncertainty. The two methods to estimate $\langle\bar{K}\rangle$ further contain systematic biases of unknown amount that could not be accounted for in the methods' uncertainties. Concerning the TRE this applies to (1) the fact that for each tracer survey about half of the tracer patch could not be sampled, and thus the deduced diapycnal extent of the patch might be biased; (2) $\langle\bar{K}\rangle_{\text {TRE }}$ being biased towards the early TRE period in which the tracer only covered a fraction of the entire region. Concerning MSS measurements this applies to (1) underlying assumptions in the train of calculating turbulent diffusivity (e.g. the value of dissipation ratio $\Gamma$ in the Osborn parameterization), (2) seasonal bias, and (3) some gaps in the sampling of the analysis box. Thus we conclude that the two $\langle\bar{K}\rangle$ estimates are not significantly different, even if the given minimum confidence limits suggest a barely statistically significant difference. Furthermore, both $\langle\bar{K}\rangle$ values can serve as estimates for $\langle\bar{K}\rangle_{\text {oxygen }}\langle\bar{K}\rangle$ of the order of $1 \times 10^{-5} \mathrm{~m}^{2} \mathrm{~s}^{-1}$ is much larger than the molecular diffusivity of heat $\left(\approx 10^{-7} \mathrm{~m}^{2} \mathrm{~s}^{-1}\right)$ and the molecular diffusivity of solutes $\left(\approx 10^{-9} \mathrm{~m}^{2} \mathrm{~s}^{-1}\right)$. Thus, molecular diffusivities are negligible, and concerning the one part of eddy diffusivity which is caused by mechanical turbulence, $\langle\bar{K}\rangle_{\text {oxygen,turb }}$ should be indistinguishable from $\langle\bar{K}\rangle_{\rho \text {,turb }}$ and $\langle\bar{K}\rangle_{\text {tracer,turb. }}$ Double diffusion could in principle enhance the diffusivity to $\langle\bar{K}\rangle_{\text {oxygen }}=\langle\bar{K}\rangle_{\text {oxygen,turb }}+\langle\bar{K}\rangle_{\text {oxygen,DD. Assuming that }}$ dissolved oxygen behaves as a tracer similar to salt, we estimate the double diffusive enhancement following the technique of St. Laurent and Schmitt (1999) to be of the order of $1 \times 10^{-6} \mathrm{~m}^{2} \mathrm{~s}^{-1}$ in the depth range $150 \mathrm{~m}$ to $500 \mathrm{~m}$ (assuming salt-finger thermal diffusivity $k_{\theta}^{(f)}$ to be $6 \times 10^{-6} \mathrm{~m}^{2} \mathrm{~s}^{-1}$ ). That means $\langle\bar{K}\rangle_{\text {oxygen }}$ might be $10 \%$ larger than $\langle\bar{K}\rangle_{\rho \text {,turb }}$ as estimated by $\langle\bar{K}\rangle_{\text {MSS/ADCP }}$, which is an insignificant difference in the range of uncertainties. $\langle\bar{K}\rangle_{\text {TRE }}$ already comprises $\langle\bar{K}\rangle_{\text {tracer,turb }}$ and $\langle\bar{K}\rangle_{\text {tracer,DD }}$ and is thus also a good estimate for $\langle\bar{K}\rangle_{\text {oxygen }}$.

The quintessence so far is that double diffusivity is negligible in the analysis depth range and turbulence is the main mixing driver, so that both $\langle\bar{K}\rangle_{\rho}$ from MSS/ADCP and $\langle\bar{K}\rangle_{\text {tracer }}$ from GUTRE can serve as appropriate estimates for $\langle\bar{K}\rangle_{\text {oxygen. }}$. The merged confidence interval for $\langle\bar{K}\rangle_{\text {oxygen }}$, as obtained from the two independent methods, is bounded by $95 \%$ confidence limits of $0.8 \times 10^{-5} \mathrm{~m}^{2} \mathrm{~s}^{-1}$ and $1.4 \times 10^{-5} \mathrm{~m}^{2} \mathrm{~s}^{-1}$.

This estimate of $1 \times 10^{-5} \mathrm{~m}^{2} \mathrm{~s}^{-1}$ is distinctly higher than the diapycnal diffusivity that could be expected for the OMZ's range of latitudes. An internal wave field with background intensity and with stratification $N^{2}$ in the observed range of 1 to $2 \times 10^{-5} \mathrm{~s}^{-2}$ should exhibit a $\langle\bar{K}\rangle$ of only some $10^{-6} \mathrm{~m}^{2} \mathrm{~s}^{-1}$ following the parameterization in Gregg et al. (2003). The higher than expected $\langle\bar{K}\rangle$ is coincident with rough bottom topography in the analysis box and an intensified internal wave field (Fischer, 2011). This aspect also fits to the finding that elevated diffusivities are found near a seamount chain in the centre of the study area. The spatial distribution of $K$ will be subject to further study and is beyond the scope of this paper.

Finally, we examine what effect a reduced sampling could have on the estimate of $\langle\bar{K}\rangle$. Comparing the esti-

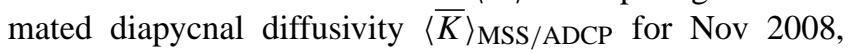
Nov/Dec 2009, and Oct 2010 (from essentially one cruise per year), we get $0.9 \times 10^{-5} \mathrm{~m}^{2} \mathrm{~s}^{-1}\left(\left[\begin{array}{lll}0.7 & 1.1] \times 10^{-5} \mathrm{~m}^{2} \mathrm{~s}^{-1}\end{array}\right.\right.$ as $95 \%$ confidence interval), $0.95 \times 10^{-5} \mathrm{~m}^{2} \mathrm{~s}^{-1} \quad([0.75$ 
1.15] $\left.\times 10^{-5} \mathrm{~m}^{2} \mathrm{~s}^{-1}\right)$, and $1.05 \times 10^{-5} \mathrm{~m}^{2} \mathrm{~s}^{-1} \quad([0.85$ $1.3] \times 10^{-5} \mathrm{~m}^{2} \mathrm{~s}^{-1}$ ), respectively. The three $\langle\bar{K}\rangle_{\mathrm{MSS} / \mathrm{ADCP}}$ estimates do not vary significantly between the years. However, each value only represents a month of survey during the last quarter of the corresponding year, so a seasonal bias cannot be ruled out. We further use the dataset

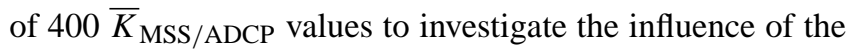
number of randomly chosen diffusivity data on the resulting uncertainty (Fig. 6), after using the same processing as used for the entire dataset. One hundred measurements (each consisting of either three MSS profiles or an ADCP recording during about a $1 \mathrm{~h}$ CTD cast) seem to be a reasonable

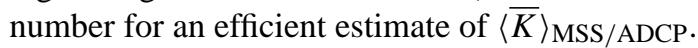

\subsection{Diapycnal oxygen flux in the analysis box}

Diapycnal diffusivities and oxygen gradients are combined to an average profile of diapycnal oxygen flux as function of density for the analysis box (Fig. 7). Here the depth interval 150 to $500 \mathrm{~m}$, for which we have $K$ estimates, roughly corresponds to the potential density range of $\sigma_{\theta}=26.55 \mathrm{~kg} \mathrm{~m}^{-3}$ to $27.1 \mathrm{~kg} \mathrm{~m}^{-3}$ in a near-linear relation. Main features of the diapycnal oxygen flux profile are two surfaces of zero average flux which coincide with positions of zero oxygen gradients: at the oxygen maximum at about $200 \mathrm{~m}$ depth and at the OMZ core at about $450 \mathrm{~m}$ depth (Fig. 4). In between these two surfaces, there is maximum downward flux of oxygen located at the deep oxycline. The depth interval of our data only allows oxygen flux calculations for the depth range $150 \mathrm{~m}$ to $500 \mathrm{~m}$ of the water column, encompassing the OMZ core and the deep oxycline. The upper surface of zero diapycnal flux at $\sigma_{\theta}=26.63 \mathrm{~kg} \mathrm{~m}^{-3}$ is situated in the upper Central Water that carries a relatively high oxygen concentration, and it exists because of the widespread presence of a shallow oxygen minimum above. The existence of the surface of zero diapycnal flux means that in the analysis box the oxygen supply to the OMZ has no direct link to the surface ocean. The diapycnal downflux of oxygen at the deep oxycline $\left(\sigma_{\theta}=26.85 \mathrm{~kg} \mathrm{~m}^{-3}\right)$ is about $(5 \pm 1) \times 10^{-3} \mu \mathrm{mol} \mathrm{m}^{-2} \mathrm{~s}^{-1}$. This flux may be interpreted as feeding the diapycnal supply of the OMZ core with about $1.5 \mu \mathrm{mol} \mathrm{kg}-1 \mathrm{yr}^{-1}$ that come via diapycnal mixing from the upper Central Water. This flux may as well be interpreted as a pure internal redistribution of oxygen inside the water body that is limited by the two surfaces of zero diapycnal flux at 200 and $450 \mathrm{~m}$.

\subsection{Sensitivity to data processing}

The processing of the diapycnal flux profile was performed in various ways, with respect to the measurement method for $K$ and the sequence of processing steps, in order to explore the sensitivity of the result to processing decisions. The reference method to obtain diapycnal flux, as defined by us, was the calculation of local flux profiles from local $K_{\text {MSS/ADCP }}$ and local oxygen gradients in small $(2 \mathrm{~m})$

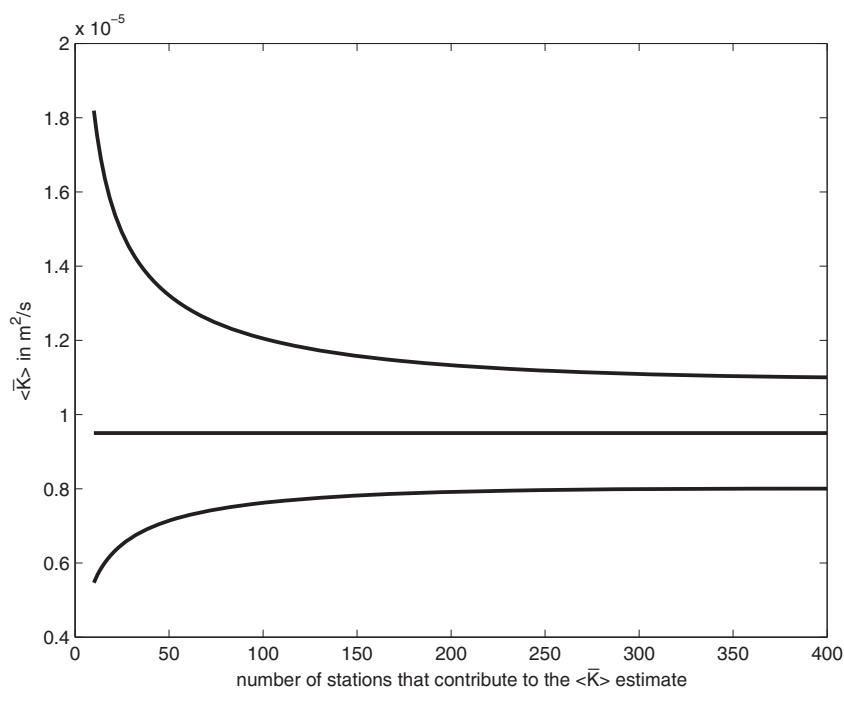

Fig. 6. Average diapycnal diffusivity $\langle\bar{K}\rangle$ in the analysis box and its $95 \%$ confidence limits when using random subsets of the available data. The full dataset comprises 400 stations of mixing data either from microstructure profiles or vessel-mounted ADCP. Processing of the subsets was identical to the full dataset.

intervals, then averaging local flux profiles isopycnally to an aggregated flux profile, and finally smoothing vertically (in a symbolic notation: $\left\langle K_{\mathrm{MSS} / \mathrm{ADCP}} \times \nabla c\right\rangle_{\text {smoothed }}$ ). Other ways of processing were tested against this reference. Swapping isopycnal averaging and flux calculation $\left(\left[\left\langle K_{\mathrm{MSS} / \mathrm{ADCP}}\right\rangle \times\langle\nabla c\rangle\right]_{\text {smoothed }}\right)$ has, as expected, little effect since $K_{\mathrm{MSS} / \mathrm{ADCP}}$ and $\nabla c$ are statistically independent in our dataset (Sect. 3.7). Thus using $\langle\bar{K}\rangle_{\mathrm{TRE}}$ to calculate diapycnal flux by $\left[\langle\bar{K}\rangle_{\mathrm{TRE}} \times\langle\nabla c\rangle\right]_{\text {smoothed }}$ essentially differs from $\left\langle\bar{K}_{\mathrm{MSS} / \mathrm{ADCP}} \times \nabla c\right\rangle_{\text {smoothed }}$ by the factor $\langle\bar{K}\rangle_{\mathrm{TRE}} /\langle\bar{K}\rangle_{\mathrm{MSS} / \mathrm{ADCP}}$. The attempt to reduce measurement error by smoothing local oxygen gradient profiles before both calculating flux and averaging isopycnally (i.e. $\langle\bar{K}\rangle_{\text {TRE }} \times\left\langle\nabla c_{\text {smoothed }}\right\rangle$ vs. $\left.\left[\langle\bar{K}\rangle_{\text {TRE }} \times\langle\nabla c\rangle\right]_{\text {smoothed }}\right)$ not only reduces noise but also systematically reduces the gradient and thus the estimated diapycnal flux (Fig. 7).

\subsection{Sensitivity to coordinate choice}

It may be worthwhile asking what the diapycnal flux across other surfaces than isopycnals is, even though then diapycnal flux is no longer perpendicular to these surfaces and there also exists an isopycnal flux component across these surfaces. Obvious coordinate choices other than isopycnal could be isobaths or surfaces that are linked to features of the oxygen field. Such a different choice primarily changes the vertical shift with which profiles of oxygen gradient get aggregated in the process of averaging laterally (i.e. along the surfaces appropriate for the chosen coordinate system). We examined two cases: (1) diapycnal flux across isobaths, and (2) diapycnal flux across a surface that connects the gradient 


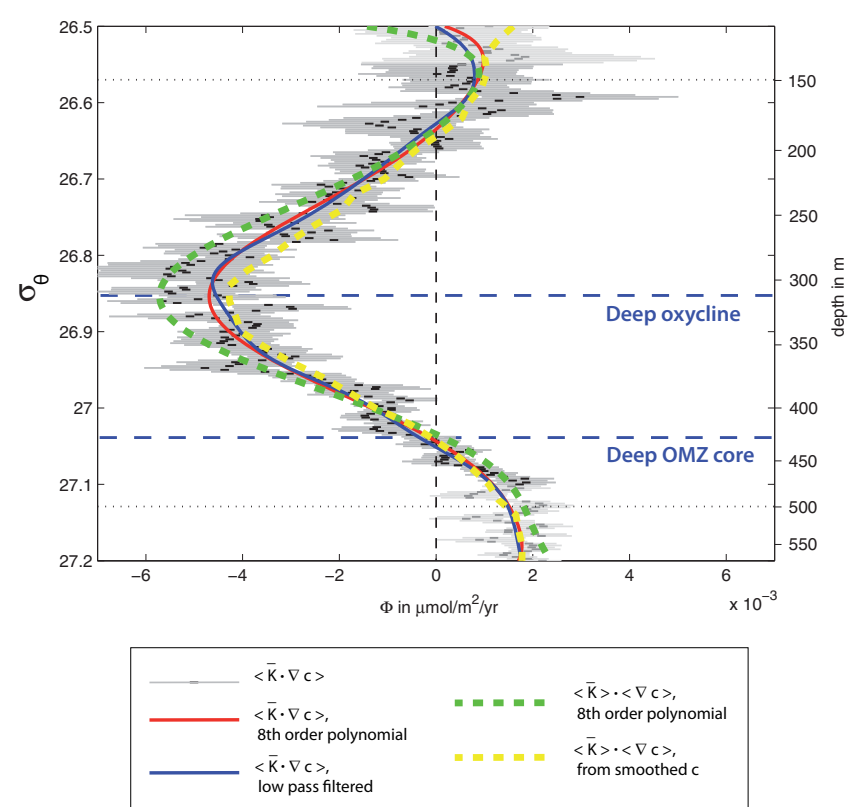

Fig. 7. Diapycnal oxygen flux in density coordinates as determined by different methods. The given smoothed curves assume that fluctuations of smaller vertical scales are an artefact of imperfect sampling. Black dots with grey shading: local oxygen gradients over $2 \mathrm{~m}$ combined with local $K$ from microstructure/ADCP measurements to local diapycnal flux, then averaged laterally along isopycnals. Red line: corresponding fitted 8th-order polynomial. Blue line: corresponding low-pass-filtered flux profile. Dashed green line: 8thorder polynomial on flux profile that was derived from horizontally averaged oxygen gradient and integral $K$ value from the tracer release experiment. Dashed yellow line: flux profile derived from vertically smoothed oxygen gradient profiles that have been laterally averaged along isopycnals before being combined with the integral $K$ value from the tracer release experiment. Dotted black lines mark the analysis depth interval 150 to $500 \mathrm{~m}$ for which $K$ estimates exist.

maxima of the deep oxycline. For case (1) the resulting diapycnal flux profile is similar in shape to the diapycnal flux profile of Fig. 7, but flux values are reduced by about $30 \%$; the downward diapycnal flux at the deep oxycline is about $3 \times 10^{-3}$ to $4 \times 10^{-3} \mu \mathrm{mol} \mathrm{m}{ }^{-2} \mathrm{~s}^{-1}$. A coordinate choice like in case (2) leads to the maximum possible estimate of downward diapycnal flux at the deep oxycline; here the resulting flux is about $6 \times 10^{-3}$ to $7 \times 10^{-3} \mu \mathrm{mol} \mathrm{m}^{-2} \mathrm{~s}^{-1}$.

\subsection{Diapycnal flux divergence and OMZ oxygen budget}

Looking at the oxygen budget of the OMZ for individual isopycnal layers allows further insight into oxygen supply than just quantifying the oxygen flux across particular surfaces. The contribution to oxygen supply by diapycnal processes, i.e. the diapycnal surplus in units of moles oxygen per volume and time, is described by the negative diapycnal flux divergence (Sect. 3.1). Of the processes contributing

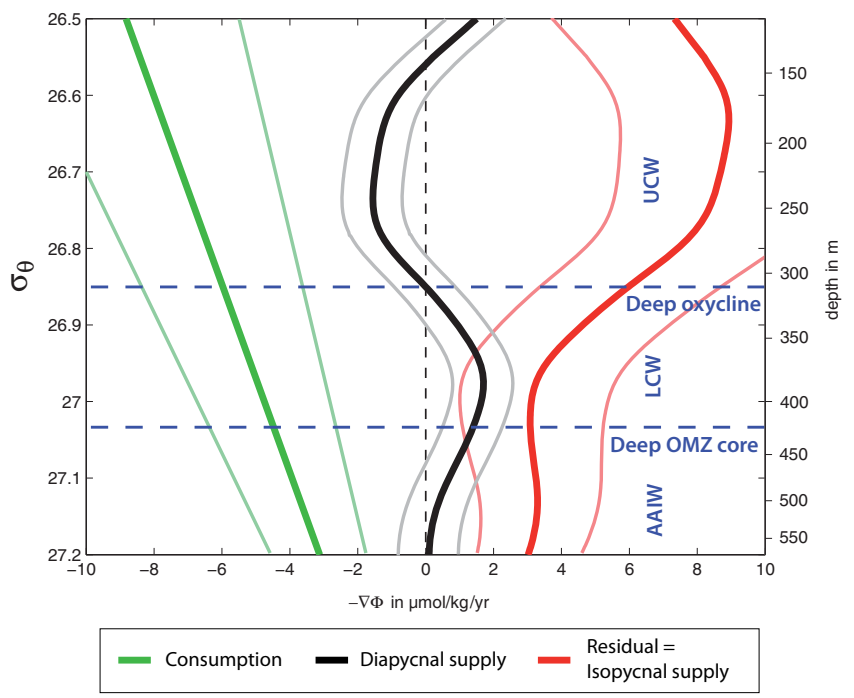

Fig. 8. Terms of the oxygen budget (diapycnal supply + isopycnal supply + consumption rate $=0$ ) as a function of density. Diapycnal supply = negative diapycnal flux divergence (black) was determined in this study (here we chose a smooth line compromising between divergences of the polynomial and the low-pass-smoothed fluxes from TRE and MSS, as in Fig. 7). Oxygen consumption rate (green) was estimated according to Karstensen et al. (2008); the exponential decrease in depth coordinates turns out to be hardly discernible from linear when transformed to isopycnal coordinates in the depth interval 150 to $500 \mathrm{~m}$. The residual that closes the budget must account for isopycnal supply (red). Uncertainties are $95 \%$ confidence limits. AAIW: Antarctic Intermediate Water; LCW: lower Central Water; UCW: upper Central Water.

to diapycnal oxygen supply, we quantified diapycnal flux by turbulent mixing (Sect. 4.2), found diapycnal flux by double diffusive convection to be negligible (Sect. 4.1), and assume diapycnal flux by diapycnal advection to be negligible in the analysed depth interval $150 \mathrm{~m}$ to $500 \mathrm{~m}$. The latter assumption is supported by diapycnal velocity estimates from the measured temperature and salinity fields and the estimated $\langle\bar{K}\rangle$ following the conservation equations given by McDougall (1991). The contribution to diapycnal supply by diapycnal advection is found this way to be very small compared to the other processes $\left(\ll 1 \mu \mathrm{mol} \mathrm{kg}^{-1} \mathrm{yr}^{-1}\right.$ at all depths). Thus for the oxygen budget of the OMZ, we only consider diapycnal oxygen supply by turbulent mixing.

Examining the vertical structure of the negative diapycnal diffusive flux divergence in Fig. 8, the maximum local diapycnal supply is located at about the OMZ core, with about 1.5 to $2 \mu \mathrm{mol} \mathrm{kg}{ }^{-1} \mathrm{yr}^{-1}$. Other distinguished locations in the flux divergence profile are the surfaces where local diapycnal supply is zero, which coincide with the locations of maximum oxygen gradients above and below the OMZ core. The upper Central Water above the deep oxycline loses oxygen to the OMZ below by diapycnal mixing, but also upwards towards the shallow oxygen minimum layer. Concerning the 
other terms of the oxygen budget - consumption rate and isopycnal supply - a consumption rate estimate may be taken from the literature, while isopycnal supply is the difference of consumption rate and diapycnal supply, assuming steady state. Reported consumption rate profiles vary throughout the global ocean and are uncertain (Keeling et al., 2010), but their principal shape is typically assumed to be exponential with depth (Martin et al., 1987; Karstensen et al., 2008). Karstensen et al. (2008) estimated an exponential consumption rate profile specific for the Atlantic and $\mathrm{Pa}$ cific OMZ regions from apparent oxygen utilization and estimated water ages. This profile is the only one reported specifically for the tropical Northeast Atlantic OMZ. It is used here with the consumption rate in $\mu \mathrm{mol} \mathrm{kg} \mathrm{gr}^{-1}$ given as $-0.5+12 \cdot \exp (-0.0021 \cdot z)$ with $z$ depth in metres. The uncertainty of the consumption rate was estimated to be $40 \%$ (95\% confidence level) from the scatter of oxygen utilization rates reported by Karstensen et al. (2008). Thus the resulting uncertainty of the deduced profile of isopycnal supply is large, but the main pattern seems clear: the profile of isopycnal oxygen supply resembles a step function, with large isopycnal supply in the upper Central Water layer above the deep oxycline, and little isopycnal supply in the OMZ layer below the deep oxycline. For a rough check of plausibility of the deduced isopycnal supply below the deep oxycline, one can use an isopycnal diffusivity of $500 \mathrm{~m}^{2} \mathrm{~s}^{-1}$ (e.g. Banyte et al., 2013) and a typical curvature of the oxygen field on an isopycnal surface of $1 \times 10^{-10} \mu \mathrm{mol} \mathrm{kg}^{-1} \mathrm{~m}^{-2}$, and obtain an estimate of $2 \mu \mathrm{mol} \mathrm{kg} \mathrm{kg}^{-1} \mathrm{yr}^{-1}$. Brandt et al. (2010) obtained consistent estimates for the isopycnal eddy supply, in an idealized framework of a mean latitudinally alternating east- and westward current system that connects the western boundary regime with the OMZ. Depending on the assumed strength of the zonal currents, they derived an isopycnal eddy supply of 0.5 to $0.9 \mu \mathrm{mol} \mathrm{kg}-1 \mathrm{yr}^{-1}$ when using an isopycnal $K$ of $200 \mathrm{~m}^{2} \mathrm{~s}^{-1}$, with the isopycnal advective supply varying between 2 and $0 \mu \mathrm{mol} \mathrm{kg}^{-1} \mathrm{yr}^{-1}$. All of these values are in the range of the expected isopycnal supply below the deep oxycline.

The assumption of steady state, which served to estimate the isopycnal supply profile, is in fact violated, and we expect a small imbalance in the oxygen budget as Stramma et al. (2008b) observed a long-term trend of $-0.35 \mu \mathrm{mol} \mathrm{kg}{ }^{-1} \mathrm{yr}^{-1}$ in the depth interval $300 \mathrm{~m}$ to $700 \mathrm{~m}$. However, this expected imbalance is much smaller than the error margins of the budget terms in Fig. 8, and thus could not be detected by observing the recent oxygen budget.

The diapycnal contribution to the supply of the tropical North Atlantic OMZ is maximum in the water layer between isopycnals 26.95 and $27.05 \mathrm{~kg} \mathrm{~m}^{-3}$, i.e. surrounding the OMZ core, and may be estimated to be about one-third of the demand, with large uncertainty.

\section{Conclusions}

The tracer release experiment and the MSS/ADCP measurements complement each other and deliver consistent estimates of diapycnal diffusivity. The two independent methods constrain diapycnal diffusivity for the OMZ in the depth range $150 \mathrm{~m}$ to $500 \mathrm{~m}$ to an inter-

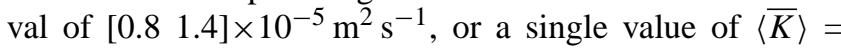
$1 \times 10^{-5} \mathrm{~m}^{2} \mathrm{~s}^{-1}$. Diapycnal diffusivity in the region is predominantly caused by turbulence, such that $\langle\bar{K}\rangle_{\text {oxygen }} \approx$ $\langle\bar{K}\rangle_{\text {solutes }} \approx\langle\bar{K}\rangle_{\rho} \approx\langle\bar{K}\rangle$. Using the diapycnal diffusivity of $1 \times 10^{-5} \mathrm{~m}^{2} \mathrm{~s}^{-1}$ could serve to constrain models and possibly improve the oxygen representation in the tropical North Atlantic OMZ.

Diapycnal oxygen supply replenishes one-third of the oxygen demand in the OMZ core (between isopycnals 26.95 and $27.05 \mathrm{~kg} \mathrm{~m}^{-3}$ ), as can be estimated from the vertical structure of diapycnal oxygen supply and consumption (Fig. 8). Thus diapycnal mixing is a major controlling process for the formation and maintenance of this OMZ and will have to be taken into account when exploring the controlling processes of other OMZs. The value "one-third" is potentially subject to some adjustments when better estimates of isopycnal supply and consumption rate become available. It will also be subject to some change in time when consumption and/or circulation and/or mixing change. Rating the diapycnal oxygen supply as a major controlling process may seem debatable: it might be equally valid to assign the oxygen supply of the OMZ entirely to isopycnal processes. If choosing a layer bounded by isopycnal surfaces $\sigma_{\theta}=26.63 \mathrm{~kg} \mathrm{~m}^{-3}$ and $27.03 \mathrm{~kg} \mathrm{~m}^{-3}$ (each characterized by zero diapycnal flux), the supply of the water column in between must be completely isopycnal, and the role of diapycnal mixing would reduce to just generating internal oxygen redistribution. But even if one adopts this latter perspective, the controlling effect of diapycnal mixing on the OMZ structure remains substantial: if diapycnal mixing was less intense than observed, the oxygen distribution in the analysis box would certainly be another. Given the other parameters kept constant, the vertical oxygen gradient would most likely become sharper, and the oxygen concentration in the OMZ core would become lower. By the same argument we also conclude that the higher than expected level of diapycnal mixing in the study region (cf. Sect. 4.1) plays a substantial role in shaping the oxygen concentration field and supposedly also in causing relatively high levels of oxygen in the core of the tropical North Atlantic OMZ compared to other OMZs. The exact reasons for the higher than expected level of diapycnal mixing will be the object of further study.

All available information combined, particularly the vertical structure of diapycnal and isopycnal supply (Fig. 8), this study also advances insight into the pathways through which oxygen is transported from abroad to the OMZ core. Besides direct isopycnal supply at all depths, there is an important supply branch which brings oxygen laterally within the upper 
Central Water layer above the deep oxycline; from there oxygen spreads diapycnally towards the OMZ core. There is no net oxygen contribution from the surface layer of the $\mathrm{OMZ}$ region because the presence of the shallow oxygen minimum causes a layer of upward average oxygen flux which virtually decouples the OMZ oxygen budget from the surface.

The contribution of diapycnal mixing to supply the lower part of the deep OMZ (below the OMZ core) with oxygen from AAIW can hardly be quantified with the present data because most measurements did not reach the necessary depths. But there are indications that diapycnal mixing is substantial here as well. Although gradient and curvature of oxygen concentration are found to be smaller below the OMZ core than above the OMZ core, turbulent diffusivity values below the OMZ core are found equal or larger than above (Fig. 4), and turbulent diffusivity is enhanced by double diffusion here (adds $50 \%$ if following the method of St. Laurent and Schmitt, 1999). The resulting total diapycnal oxygen flux from below might even reach similar values to those above, while the oxygen consumption rate to be balanced is lower than above. Another TRE will elucidate the relative importance of diapycnal and isopycnal supply for the layer at and below the OMZ core. This TRE (Oxygen Supply Tracer Release Experiment, OSTRE) was launched in December 2012, and surveys are scheduled from June 2013 until 2015 and include ADCP and microstructure profiles down to $800 \mathrm{~m}$.

The uncertainty of the consumption profile is causing high uncertainty in the estimated profile of isopycnal supply (however, some confidence to the magnitude of isopycnal supply is inspired by the independent rough calculations of isopycnal oxygen supply given in Section 4.5). Local profiles of consumption rate are still difficult to obtain (e.g. Keeling et al., 2010) but are important for evaluating the oxygen budget. Nevertheless, the general tendency of consumption rate to diminish with depth seems to be described well enough by the fitted exponential of Karstensen et al. (2008), and moderate deviations from that profile would not change the main features of the deduced isopycnal oxygen supply profile as of Fig. 8. In fact, some deviation from an exponential shape seems even probable, e.g. caused by active organic matter transport during diel vertical migration of zooplankton (Angel, 1985; Steinberg et al., 2002). The local impact of the latter process on the OMZ is unknown, but collected acoustic data during the survey cruises showed strong diel migrant activity. The acoustic backscatter records suggest enhanced oxygen consumption at about $300 \mathrm{~m}$ and diminished oxygen consumption at about $200 \mathrm{~m}$ depth. This is a shape not uncommon in reported consumption profiles for the Pacific (Feely et al., 2004), but on their reported level the effect would be small: the jump in the isopycnal supply profile of Fig. 8 would shift slightly downwards, but the profile's principal shape would not change.

What is the reason for the found sharp decline of isopycnal oxygen supply at the depth of the deep oxycline? This contrast in isopycnal oxygen supply could basically origi-

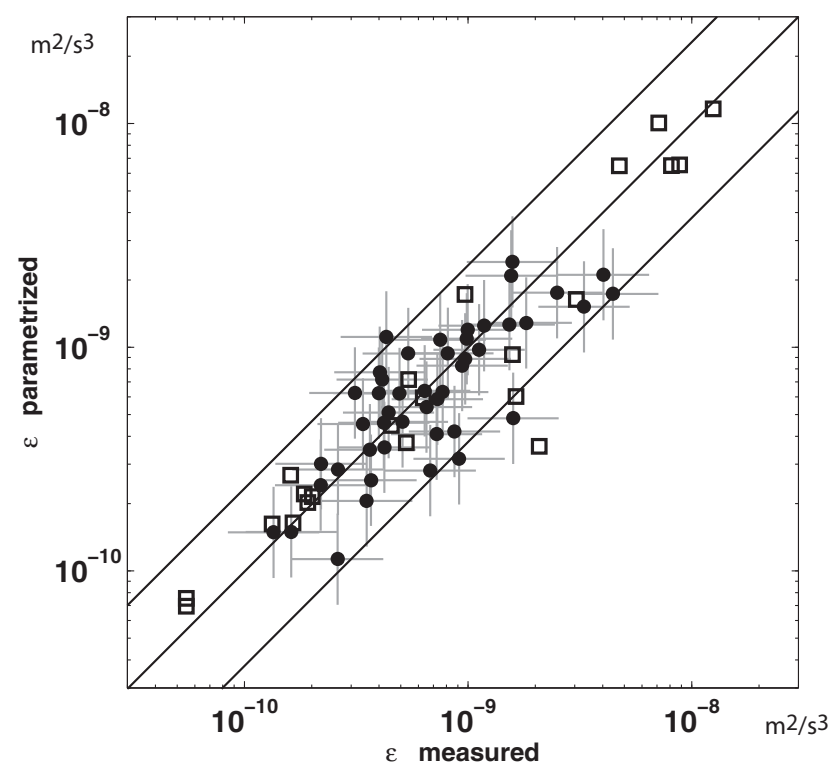

Fig. 9. Predicted versus measured turbulent dissipation rates. Predictions by parameterization $\epsilon=1 / 100 \cdot f^{5 / 9} \cdot N^{19 / 9} \cdot G^{4 / 3}$ that resulted from a two-parameter fit in $\Psi_{1}=N^{2} \cdot G$ (vertical shear power) and $\Psi_{2}=f \cdot N^{-1}$ (internal wave slope). Measurements by microstructure profiler MSS90D in the region of the tropical North Atlantic OMZ (black dots) and values reported by Polzin et al. (1995) performed with the High Resolution Profiler in different midlatitude locations (squares). Of the total predictions, $95 \%$ lie within a factor 2.5 from measured values.

nate in isopycnal eddy diffusion and/or isopycnal advection. However, several potential explanations for the sharp contrast seem improbable: we do not expect lateral diffusivities to experience a jump at the deep oxycline, nor do we expect a vertical jump of proper sign in the second derivative of isopycnal oxygen distribution (supported by WOA09 climatological data; Garcia et al., 2010). This makes eddy processes an improbable reason for the sharp decline. Furthermore, we do not expect mean current velocities to jump in magnitude or direction at the depth of the deep oxycline. Thus it is suggested that the main contribution to the shape of isopycnal oxygen supply is due to advection of water carrying specific oxygen profiles when entering and leaving the OMZ region. Water of greater than average vertical oxygen gradient would enter the OMZ region, would undergo depth-dependent consumption and a diapycnal redistribution of oxygen inside the region, and would leave the region with a weaker than average vertical oxygen gradient. The OMZ region would just act to reduce the oxygen gradient at the deep oxycline, and the source of water with a strong oxygen gradient would have to be sought outside the OMZ region. The western boundary circulation characterized by strong vertical shear is a likely candidate for generating sharp vertical oxygen gradients that could be transported within eastward current bands into the OMZ. 
Finally, this study can help planning and data processing in similar studies by giving hints on the necessary measurement effort to obtain $\langle\bar{K}\rangle$ estimates (Fig. 6) and by making use of the found lateral independence of $\bar{K}$ and vertical oxygen gradient. The latter feature allowed us to estimate the average diapycnal oxygen flux in the OMZ region from the regional average of diapycnal diffusivity and the regional average of the oxygen gradient profile (further assuming that these averages are representative for the analysis box). If such an independence of $\bar{K}$ and concentration gradients is also valid for other regions and substances, regional diapycnal fluxes can be estimated from datasets which comprise non-simultaneous measurements.

\section{Appendix A}

\section{Dissipation rate parameterized from vessel-mounted ADCP data}

There is a widely known parameterization of dissipation rate $\epsilon$ for the open ocean (Polzin et al., 1995; Gregg et al., 2003) which is based on the concept of breaking internal waves causing turbulence, dissipation, and mixing. Important parameters needed to use this parameterization are finescale vertical shear and finescale vertical strain; "finescale" in this context comprises vertical wavenumbers of the order of 10 to order $100 \mathrm{~m}$. In this study, we had access to vertical shear via vmADCP data (Sect. 3.6), but for strain we lacked simultaneous data of satisfying quality. As a remedy we fitted another parameterization with fewer parameters, using our own data from the tropical North Atlantic Ocean plus data from midlatitudes, which were reported by Polzin et al. (1995) and formed the base of their parameterization. Here two variables were used which have commonly been identified to influence mixing intensity in the open ocean: (1) the intensity of velocity vertical shear in the vertical wavelength band of tens to hundreds of metres as providing the forcing, and (2) the characteristic slope of internal waves, which influences their probability to break and cause turbulence, dissipation, and mixing. The predictors $\Psi_{1}$ and $\Psi_{2}$ we defined for the parameterization were derived from these two variables, having been inspired by the Garrett-Munk (GM) internal wave model (Garrett and Munk, 1975; Munk, 1981). $\Psi_{1}$ was chosen proportional to the power spectral level $\Phi_{\mathrm{S}}$ of vertical finescale shear as follows:

$\Psi_{1}=N^{2} \cdot G$,

with $N$ buoyancy frequency and $G$ a nondimensional number describing the power spectral level of shear, $\Phi_{\mathrm{S}}$, in relation to its GM background level $\Phi_{\mathrm{S}, \mathrm{GM}}=$ const. $\cdot N^{2}$. $G$ was estimated from vmADCP data by

$G=\frac{\Phi_{\mathrm{S}}^{k_{\min } \ldots k_{\max }}}{\Phi_{\mathrm{S}, \mathrm{GM}}^{k_{\min } \ldots k_{\max }}}$, and both $\Phi_{\mathrm{S}}^{k_{\min } \ldots k_{\max }}$ and $\Phi_{\mathrm{S}, \mathrm{GM}}^{k_{\min } \ldots k_{\max }}$ were calculated in the vertical wavenumber range $k_{\min }=1 / 128 \mathrm{cpm}$ to $k_{\max }=1 / 38.4 \mathrm{cpm}$ by weighted averaging as $\Sigma((9-i) / 8$. $\left.\Phi_{S, i}\right) / \Sigma((9-i) / 8)$ for the appropriate $\Phi_{S, i}$ at wavenumbers $k_{i}=(2+i) / 384 \mathrm{cpm}$. This way to estimate $G$ is specific to the used vmADCP configuration and the used depth interval for the analysis of 150 to $500 \mathrm{~m}$. But $G$ is not expected to be sensitive to the particular choice of $k_{i}$ in the finescale range. $\Psi_{2}$ was chosen as follows:

$\Psi_{2}=\frac{f}{N}$,

with $f$ the Coriolis parameter because the characteristic slope of the internal wave field approximately is a power of $f \cdot N^{-1}$ when assuming the GM model. In order to fit a regression model we took the existing 45 stations with simultaneous microstructure profiles, CTD profile, and vmADCP measurements, plus data from the High Resolution Profiler collected at several midlatitude locations as reported by Polzin et al. (1995). Predictor $\Psi_{1}$ relied on vmADCP data for $G$ and CTD data for $N^{2}$, predictor $\Psi_{2}$ needed latitude and CTD data for $N$, and predictand $\epsilon$ was provided by microstructure data. In order to avoid a skewed distribution in parameter space, we performed linear regression in logarithmic space, i.e. the regression model was $\log \epsilon=a_{0}+a_{1} \cdot \log$ $\Psi_{1}+a_{2} \cdot \log \Psi_{2}$. The best model fit (Fig. 9) can be written as follows:

$\epsilon=\frac{1}{100} \cdot \Psi_{1}^{4 / 3} \cdot \Psi_{2}^{5 / 9}$,

with multiple correlation $R^{2}=0.80$. This relation translates to

$\epsilon=\frac{1}{100} \cdot f^{5 / 9} \cdot N^{19 / 9} \cdot G^{4 / 3}$.

Acknowledgements. This study benefitted from cruises, infrastructure, and financial support by the German Federal Ministry of Education and Research through the cooperative projects SOPRAN and NORTH ATLANTIC, and by the German Science Foundation's Sonderforschungsbereich SFB754 "Climate Biogeochemistry Interactions in the Tropical Ocean". We acknowledge the support of the European Commission (FP7-EuroSITES grant agreement no. 202955). The support of captains, crews, and scientific crews of Meteor cruise 80, Meteor cruise 83/1, Merian cruise 08/1, Merian cruise 10/1, and L'Atalante cruises GEOMAR/3 and GEOMAR/4 is highly appreciated. We thank Johannes Karstensen for fruitful discussions. We thank two anonymous reviewers, who helped to improve the manuscript.

The service charges for this open access publication have been covered by a Research Centre of the Helmholtz Association.

Edited by: B. Dewitte 


\section{References}

Angel, M. V.: Vertical migrations in the oceanic realm: possible causes and probable effects, in: Migration: Mechanisms and Adaptive Significance, Contributions in Marine Science, suppl. Vol. 27, edited by: Rankin, M. A., Checkley, D., Cullen, J., Kitting, C., and Thomas, P., Marine Science Institute, Austin, Texas, 45-70, 1985.

Banyte, D., Tanhua, T., Visbeck, M., Wallace, D. W. R., Karstensen, J., Krahmann, G., Schneider, A., Stramma, L., and Dengler, M.: Diapycnal diffusivity at the upper boundary of the tropical North Atlantic oxygen minimum zone, J. Geophys. Res., 117, C09016, doi:10.1029/2011JC007762, 2012.

Banyte, D., Visbeck, M., Tanhua, T., Fischer, T., Krahmann, G., and Karstensen, J.: Lateral diffusivity from tracer release experiments in the tropical North Atlantic thermocline, J. Geophys. Res. Oceans, 118, doi:10.1002/jgrc.20211, 2013.

Bograd, S. J., Castro, C. G., Di Lorenzo, E., Palacios, D. M., Bailey, H., Gilly, W., and Chavez, F. P.: Oxygen declines and the shoaling of the hypoxic boundary in the California Current, Geophys. Res. Lett., 35, L12607, doi:10.1029/2008GL034185, 2008.

Bopp, L., Monfray, P., Aumont, O., Dufresne, J.-L., Le Treut, H., Madec, G., Terray, L., and Orr, J. C.: Potential impact of climate change on marine export production, Global Biogeochem. Cy., 15, 81-99, 2001.

Bopp, L., Le Quere, C., Heimann, M., and Manning, A. C.: Climate-induced oceanic oxygen fluxes: Implications for the contemporary carbon budget, Global Biogeochem. Cy., 16, 1022, doi:10.1029/2001GB001445, 2002.

Brandt, P., Hormann, V., Körtzinger, A., Visbeck, M., Krahmann, G., Stramma, L., Lumpkin, R., and Schmid, C.: Changes in the Ventilation of the Oxygen Minimum Zone of the Tropical North Atlantic, J. Phys. Oceanogr., 40, 1784-1801, doi:10.1175/2010JPO4301.1, 2010.

Davis, R. E.: Sampling turbulent dissipation, J. Phys. Oceanogr., 26, 341-358, 1996.

Diaz, R. J.: Overview of Hypoxia around the World, J. Environ. Qual., 30, 275-281, 2001.

Duteil, O. and Oschlies, A.: Sensitivity of simulated extent and future evolution of marine suboxia to mixing intensity, Geophys. Res. Lett., 38, L06607, doi:10.1029/2011GL046877, 2011.

Ekau, W., Auel, H., Pörtner, H.-O., and Gilbert, D.: Impacts of hypoxia on the structure and processes in pelagic communities (zooplankton, macro-invertebrates and fish), Biogeosciences, 7 , 1669-1699, doi:10.5194/bg-7-1669-2010, 2010.

Feely, R. A., Sabine, C. L., Schlitzer, R., Bullister, J. L., Mecking, S., and Greeley, D.: Oxygen utilization and organic carbon remineralization in the upper water column of the Pacific Ocean, J. Oceanogr., 60, 45-52, 2004.

Ferrari, R. and Polzin, K. L.: Finescale Structure of the T-S Relation in the Eastern North Atlantic, J. Phys. Oceanogr., 35, 1437-1454, 2005.

Fischer, T.: Diapycnal diffusivity and transport of matter in the open ocean estimated from underway acoustic profiling and microstructure profiling, Ph.D. thesis, Leibniz Institute of Marine Sciences (GEOMAR), University of Kiel, Germany, 105 pp., 2011.

Garcia, H. E., Locarnini, R. A., Boyer, T. P., Antonov, J. I., Baranova, O. K., Zweng, M. M., and Johnson, D. R.: World Ocean Atlas 2009 Volume 3 (Dissolved Oxygen, Apparent Oxygen
Utilization, and Oxygen Saturation), NOAA Atlas NESDIS 70, edited by: Levitus, S., US Government Printing Office, Washington, DC, 344 pp., 2010.

Gargett, A. E.: An investigation of the occurrence of oceanic turbulence with respect to finestructure, J. Phys. Oceanogr., 6, 139156, 1976.

Garrett, C. and Munk, W.: Space-time scales of internal waves: A progress report, J. Geophys. Res., 80, 291-297, 1975.

Gregg, M. C.: Scaling turbulent dissipation in the thermocline, J. Geophys. Res., 94, 9686-9698, 1989.

Gregg, M., Sanford, T. B., and Winkel, D. P.: Reduced mixing from the breaking of internal waves in equatorial waters, Nature, 422, 513-515, 2003.

Gruber, N.: Warming up, turning sour, losing breath: ocean biogeochemistry under global change, Philos. T. Roy. Soc. A, 369, 1980-1996, doi:10.1098/rsta.2011.0003, 2011.

Hales, B., Moum, J. N., Covert, P., and Perlin, A.: Irreversible nitrate flux due to turbulent mixing in a coastal upwelling system, J. Geophys. Res., 110, C10S11, doi:10.1029/2004JC002685, 2005.

Hales, B., Hebert, D., and Marra, J.: Turbulent supply of nutrients to phytoplankton at the New England shelf break front, J. Geophys. Res., 114, C05010, doi:10.1029/2008JC005011, 2009.

Helm, K. P., Bindoff, N. L., and Church, J. A.: Observed decreases in oxygen content of the global ocean, Geophys. Res. Lett., 38, L23602, doi:10.1029/2011GL049513, 2011.

Ho, D. T., Ledwell, J. R., and Smethie Jr., W. M.: Use of $\mathrm{SF}_{5} \mathrm{CF}_{3}$ for ocean tracer release experiments, Geophys. Res. Lett., 35, L04602, doi:10.1029/2007GL032799, 2008.

Karstensen, J., Stramma, L., and Visbeck, M.: Oxygen minimum zones in the eastern tropical Atlantic and Pacific oceans, Prog. Oceanogr., 77, 331-350, doi:10.1016/j.pocean.2007.05.009, 2008.

Keeling, R. F., Körtzinger, A., and Gruber, N.: Ocean deoxygenation in a warming world, Annu. Rev. Mar. Sci., 2, 199-229, doi:10.1146/annurev.marine.010908.163855, 2010.

Kirchner, K., Rhein, M., Hüttl-Kabus, S., and Böning, C. W.: On the spreading of South Atlantic Water into the Northern Hemisphere, J. Geophys. Res., 114, C05019, doi:10.1029/2008JC005165, 2009.

Kock, A., Schafstall, J., Dengler, M., Brandt, P., and Bange, H. W.: Sea-to-air and diapycnal nitrous oxide fluxes in the eastern tropical North Atlantic Ocean, Biogeosciences, 9, 957-964, doi:10.5194/bg-9-957-2012, 2012.

Kunze, E., Firing, E., Hummon, J. M., Chereskin, T. K., and Thurnherr, A. M.: Global abyssal mixing inferred from lowered ADCP shear and CTD strain profiles, J. Phys. Oceanogr., 36, 15531576, 2006.

Lam, P. and Kuypers, M. M. M.: Microbial nitrogen cycling processes in oxygen minimum zones, Annu. Rev. Mar. Sci., 3, 317345, doi:10.1146/annurev-marine-120709-142814, 2011.

Martin, J. H., Knauer, G. A., Karl, D. M., and Broenkow, W. W.: VERTEX: carbon cycling in the northeast Pacific, Deep-Sea Res., 34, 267-285, 1987.

Matear, R. J. and Hirst, A. C.: Long-term changes in dissolved oxygen concentrations in the ocean caused by protracted global warming, Global Biogeochem. Cy., 17, 1125, doi:10.1029/2002GB001997, 2003.

McDougall, T. J.:Water Mass Analysis with Three Conservative Variables, J. Geophys. Res., 96, 8687-8693, 1991. 
Meissner, K. J., Galbraith, E. D., and Völker, C.: Denitrification under glacial and interglacial conditions: A physical approach, Paleoceanography, 20, PA3001, doi:10.1029/2004PA001083, 2005.

Munk, W. H.: Internal waves and small-scale processes, in: Evolution of Physical Oceanography; Scientific Surveys in Honor of Henry Stommel, edited by: Warren, B. A. and Wunsch, C., MIT press, Cambridge and London, 264-291, 1981.

Najjar, R. G., Jin, X., Louanchi, F., Aumont, O., Caldeira, K., Doney, S. C., Dutay, J.-C., Follows, M., Gruber, N., Joos, F., Lindsay, K., Maier-Reimer, E., Matear, R. J., Matsumoto, K., Monfray, P., Mouchet, A., Orr, J. C., Plattner, G.-K., Sarmiento, J. L., Schlitzer, R., Slater, R. D., Weirig, M.-F., Yamanaka, Y., and Yool, A.: Impact of circulation on export production, dissolved organic matter, and dissolved oxygen in the ocean: results from phase II of the Ocean Carbon-cycle Model Intercomparison Project (OCMIP-2), Global Biogeochem. Cy., 21, GB3007, doi:10.1029/2006GB002857, 2007.

Oakey, N. S.: Determination of the rate of dissipation of turbulent energy from simultaneous temperature and velocity shear microstructure measurements, J. Phys. Oceanogr., 12, 256-271, 1982.

Osborn, T. R.: Estimates of the local rat of vertical diffusion from dissipation measurements, J. Phys. Oceanogr., 10, 83-89, 1980.

Oschlies, A., Schulz, K. G., Riebesell, U., and Schmittner, A.: Simulated 21st century's increase in oceanic suboxia by $\mathrm{CO}_{2-}$ enhanced biotic carbon export, Global Biogeochem. Cy., 22, GB4008, doi:10.1029/2007GB003147, 2008.

Paulmier, A. and Ruiz-Pino, D.: Oxygen minimum zones (OMZs) in the modern ocean, Prog. Oceanogr., 80, 113-128, doi:10.1016/j.pocean.2008.08.001, 2009.

Polzin, K. L., Toole, J. M., and Schmitt, R. W.: Finescale parameterizations of turbulent dissipation, J. Phys. Oceanogr., 25, 306328, 1995.

Polzin, K., Kunze, E., Hummon, J., and Firing, E.: The finescale response of lowered ADCP velocity profiles, J. Atmos. Ocean. Tech., 19, 205-224, 2002.

Prince, E. D., Luo, J., Goodyear, C. P., Hoolihan, J. P., Snodgrass, D., Orbesen, E. S., Serafy, J. E., Ortiz, M., and Schirripa, M. J.: Ocean scale hypoxia-based habitat compression of atlantic istiophorid billfishes, Fish. Oceanogr., 19, 448-462, doi:10.1111/j.1365-2419.2010.00556.x, 2010.

Rippeth, T. P., Wiles, P., Palmer, M. R., Sharples, J., and Tweddle, J.: The diapycnal nutrient flux and shear-induced diapycnal mixing in the seasonally stratified western Irish Sea, Continental Shelf Res., 29, 1580-1587, doi:10.1016/j.csr.2009.04.009, 2009.

Schafstall, J., Dengler, M., Brandt, P., and Bange, H. W.: Tidalinduced mixing and diapycnal nutrient fluxes in the Mauritanian upwelling region, J. Geophys. Res., 115, C10014, doi:10.1029/2009JC005940, 2010.

Sharples, J., Moore, C. M., and Abraham, E. R.: Internal tide dissipation, mixing, and vertical nitrate flux at the shelf edge of NE New Zealand, J. Geophys. Res., 106, 14069-14081, 2001.
Sharples, J., Tweddle, J. F., Green, J. A. M., Palmer, M. R., Kim, Y.N., Hickman, A. E., Holligan, P. M., Moore, C. M., Rippeth, T. P., Simpson, J. H., and Krivtsov, V.: Spring-neap modulation of internal tide mixing and vertical nitrate fluxes at a shelf edge in summer, Limnol. Oceanogr., 52, 1735-1747, 2007.

Shih, L. H., Koseff, J. R., Ivey, G. N., and Ferziger, J. H.: Parameterization of turbulent fluxes and scales using homogeneous sheared stably stratified turbulence simulations, J. Fluid Mech., 525, 193 214, 2005.

Siedler, G., Zangenberg, N., and Onken, R.: Seasonal changes in the tropical Atlantic circulation: observation and simulation of the guinea dome, J. Geophys. Res., 97, 703-715, 1992.

Staquet, C. and Sommeria, J.: Internal gravity waves: from instabilities to turbulence, Annu. Rev. Fluid Mech., 34, 559-593, 2002.

Steinberg, D. K., Goldthwait, S. A., and Hansell, D. A.: Zooplankton vertical migration and the active transport of dissolved organic and inorganic nitrogen in the Sargasso Sea, Deep-Sea Res. Pt. I, 49, 1445-1461, 2002.

Stips, A. and Prandke, H.: Recommended Algorithm for Dissipation Rate calculation within PROVESS, European Commission, JRC, Space Applications Institute, Technical Note No. 1.00.116, available at: www.pol.ac.uk/provess/bodc/doc/dissi_algo.pdf (last access: 10 October 2012), 2000.

St. Laurent, L. and Schmitt, R. W.: The contribution of salt fingers to vertical mixing in the North Atlantic Tracer Release Experiment, J. Phys. Oceanogr., 29, 1404-1424, 1999.

Stramma, L., Brandt, P., Schafstall, J., Schott, F., Fischer, J., and Körtzinger, A.: Oxygen minimum zone in the North Atlantic south and east of the Cape Verde islands, J. Geophys. Res., 113, C04014, doi:10.1029/2007JC004369, 2008a.

Stramma, L., Johnson, G. C., Sprintall, J., and Mohrholz, V.: Expanding Oxygen-Minimum Zones in the Tropical Oceans, Science, 320, 655-658, doi:10.1126/science.1153847, 2008b.

Stramma, L., Visbeck, M., Brandt, P., Tanhua, T., and Wallace, D. W. R.: Deoxygenation in the oxygen minimum zone of the eastern tropical North Atlantic, Geophys. Res. Lett., 36, L20607, doi:10.1029/2009GL039593, 2009.

Stramma, L., Schmidtko, S., Levin, L. A., and Johnson, G. C. Ocean oxygen minima expansions and their biological impacts, Deep-Sea Res. Pt. I, 57, 587-595, doi:10.1016/j.dsr.2010.01.005, 2010.

Vaquer-Sunyer, R. and Duarte, C. M.: Thresholds of hypoxia for marine biodiversity, P. Natl. Acad. Sci. USA, 105, 15452-15457, doi:10.1073/pnas.0803833105, 2008.

Whitney, F. A., Freeland, H. J., and Robert, M.: Persistently declining oxygen levels in the interior waters of the eastern subarctic Pacific, Prog. Oceanogr., 75, 179-199, doi:10.1016/j.pocean.2007.08.007, 2007.

Wright, J. J., Konwar, K. M., and Hallam, S. J.: Microbial ecology of expanding oxygen minimum zones, Nat. Rev. Microbiol., Advance Online Publications, doi:10.1038/nrmicro2778, 2012.

Wyrtki, K.: The oxygen minima in relation to ocean circulation, Deep-Sea Res., 9, 11-23, 1962. 